Article

\title{
Pumping Schedule Optimization in Acid Fracturing Treatment by Unified Fracture Design
}

\author{
Rahman Lotfi ${ }^{1}$, Mostafa Hosseini ${ }^{* 1}$, and Davood Aftabi ${ }^{1}$, Alireza Baghbanan ${ }^{1}$, and Guanshui $\mathbf{X u}^{2}$
}

1 Department of Mining Engineering, Isfahan University of Technology, Isfahan, Iran. Post Code 8415683111

2 Department of Mechanical Engineering, University of California, Riverside

; Lotfi_rahman@ymail.com (R.L.); Davoodaftabi2013@gmail.com (D.A.); Bagh110@kth.se (A.B.); gxu@engr.ucr.edu (G.X.)

* Correspondence: mostafahosseinimhm@yahoo.com

\begin{abstract}
Acid fracturing simulation is used widely to optimize carbonate reservoirs and improve acid fracturing treatment performance. In this study, a method was used to minimize the risk of the acid fracturing treatment. First, optimal fracture geometry parameters with UFD methods are calculated. After that, design components change as long as fracture geometry parameters reach their optimal values. The results showed a high flow rate needed to achieve optimal fracture geometry parameters with increasing acid volume. Sensitivity analysis was performed on controllable and reservoir parameters. It observed that a high flow rate should be applied for a low fluid viscosity to achieve the optimization goals. Straight acid reaches optimal conditions at a high flow rate and low volume. These conditions for retarded acids appear only at a low flow rate and high volume. The study of the acid concentration for gelled acid showed that as it increased, the flow rate and volume increased. Besides, for low permeability formation, a large fracture half-length and small fracture width are desirable. In this case, a higher flow rate will be required. The sensitivity analysis showed that the optimum flow rate and acid volume increase and decrease for the high Young's modulus. The effect of closure stress was also investigated and observed for a sample with high closure stress, low flow rate, and high acid volume are required.
\end{abstract}

Keywords: Acid fracturing; UFD; Optimization; Fracture geometry; Acid type; Design parameters

\section{Introduction}

Acid fracturing treatment is used widely to improve well-performance in carbonate reservoirs. The first stage of the acid fracturing treatment creates an initial fracture by applying pressure higher than the formation breakdown pressure. At this stage, a nonreactive fluid called Pad is injected. In order to facilitate rock dissolution on the fracture walls created by the Pad, acid is injected into the well. At the end of the treatment, the pressure is released, and the fracture is allowed to close by the in-situ stress. However, due to the removal of the rock at the fracture walls, the fracture does not close entirely and improves the hydraulic connection of the well to the reservoir.

In the last few decades, extensive studies on the acid fracturing process emphasizing acid-induced dissolution and acid-etched width were conducted. An acid transport equation for the one-dimensional steady-state is presented[1,2]. Also, a method was established to describe the matrix acidizing, considering all the variables[3]. Schechter (1992) assumed that all flow entering between the plates uniformly leaks out the channel and calculated velocity profiles with Berman's method[4,5]. Hill et al. (1995) present a leak-off model that includes the wormhole's effect on the acid fracturing[6]. In this model, overall fluid leak-off is controlled by three mechanisms. These mechanisms include reservoir fluid compressibility, the thickness of the invaded zone, and Filter cake formed on the fracture wall. Gdanski and lee (1989) developed a fracture acidizing simulator method 
that considered the effect of parameters such as fracture geometry, temperature calculations, and acid spending process[7]. Navarrete et al. (1998) investigated the effect of acid retardation on the resulting acid-etched width[8].

In order to achieve realistic results and minimize the limitations of analytical methods, numerical methods have been developed. Lo and Dean (1989) calculate the two-dimensional diffusion-convection equation by considering an average for acid concentration along the fracture width[9]. Settari et al. (2001) developed a two-dimensional model of acid transport in the un-steady state by considering the flow influence in two directions of length and width and minor changes in the direction of fracture height[10]. Romero et al. (2001), developed a model to eliminate the effect of mass transfer coefficient on the calculation of acid transported to the fracture walls[11]. They considered the influence of the acid transfer in the direction of the fracture walls. Mou et al. (2010) developed a fully three-dimensional model using the SIMPLEM algorithm[12]. They calculated the 3D velocity fields for an intermediate-scale acid fracture model and simulated the acid transport process within a random region of the acid fracturing. Mou method was modified for the field scale of the acid fracturing treatment[13]. Aljawad et al. (2016) investigated the effects of the three types of acid systems on fracture conductivity and acid penetration distance[14]. Alhubail et al. (2017) developed an acid transport model using the finite element method to improve treatment efficiency[15]. Ugursal et al. (2018) presented a new model for predicting acid fracturing performance in naturally fractured carbonate reservoirs and investigated the effect of natural fractures on acid fracturing stimulation efficiency[16]. Dang et al. (2019). modeled acid filtration in the fractured reservoir to investigate acid filtration in natural fractures, wormholes, and matrix on acid injection distance[17].

An important issue that can reduce the cost and risk of acid fracturing treatment is acid fracturing optimization. Ben-Naceur and Economides (1989) presented a model coupling fracture geometry to the diffusion mechanism[18]. Guo et al. (2004) researched three-dimensional modeling of acid fracturing and optimization design, and they proposed a technique for achieving the maximum net present value[19]. Ravikumar et al. (2015) presented a method to estimate the optimum length and conductivity using the UFD approach[20]. Ai et al. (2018) coupled the fracture geometry optimization with treatment parameter optimization to maximize the dimensionless productivity index[21]. Aljawad et al. (2020) used a comprehensive acid fracturing model to optimize design parameters[22,23]. Aljawad et al. (2020) proposed a method to investigate the effect of diversion on acid fracturing of laminated carbonate formations[24]. Al-Ameri et al. (2020) employed FRACPRO software to optimize acid fracturing design for a tight carbonate reservoir to investigate the impact of acid injection stages and acid fluids types on the fracture geometry parameters and the fracture conductivity[25]. Hassan et al. (2021) presented a simple and computationally efficient model for evaluating acid fracturing efficiency in naturally fractured reservoirs using artificial intelligence-based techniques [26].

Pumping schedule optimization with all these methods requires desirable conditions to be selected manually between several options. The primary purpose of this paper is to minimize the risk of the acid fracturing treatment. Therefore, some iterative simulations were performed to optimization of the fracture geometry parameters using the UFD approach. Therefore, design parameters were changed to each specified optimization goal.

\section{Methodology}

\subsection{Workflow}

Figure 1 illustrates the workflow of the proposed method. First, the initial data listed in Table 1 are entered into the model. Data include formation and rock properties, acid properties, and parameters of the UFD method. Then, optimum fracture geometry parameters for a specific volume are calculated using the UFD method. In the next step, consider an initial guess for injected flow rate. After that, the flow rate is changed to achieve the fracture optimum geometry parameters. As reported in previous studies, the fracture propagation and acid transport models are simulated for a specific flow rate [13,27]. The 
condition of convergence is to minimize the equation (1). It should be noted that an optimum flow rate is estimated for any specific acid volume estimates. This process continues until the final acid volume is reached.

$$
\text { Error }=\sqrt{\left(\frac{x_{f}}{x_{O p t}}-1\right)^{2}+\left(\frac{\bar{w}_{\text {Acid }}}{w_{\text {Opt }}}-1\right)^{2}}
$$

Where $x_{f}$ is estimated fracture half-length for a specific flow rate, $x_{O p t}$ is optimal fracture half-length, $\bar{w}_{\text {Acid }}$ is estimated average acid-etched width for a specific flow rate and $w_{O p t}$ is the optimal fracture width.

Table 1. Data required by the proposed method.

\begin{tabular}{|c|c|c|}
\hline Parameter & Value & Unit \\
\hline \multicolumn{3}{|c|}{ Formation properties } \\
\hline Young's Modulus (E) & 6 & MMPsi \\
\hline Poisson Ratio $(v)$ & 0.25 & - \\
\hline Porosity $(\varnothing)$ & 0.071 & - \\
\hline Permeability (k) & 0.4 & md \\
\hline Wormhole breakthrough pore volume $\left(Q_{i b t}\right)$ & 1.5 & - \\
\hline Layer Thickness $(\mathrm{H})$ & 50 & $\mathrm{~m}$ \\
\hline Closure Stress $\left(\sigma_{c}\right)$ & 4200 & Psi \\
\hline Total compressibility $\left(C_{t}\right)$ & $1.983 \mathrm{E}-05$ & $P s i^{-1}$ \\
\hline Reservoir Oil Viscosity $\left(\mu_{\text {Oil }}\right)$ & 1.66 & $\mathrm{cp}$ \\
\hline Formation Rock Density $\left(\rho_{\text {Rock }}\right)$ & 2600 & $\mathrm{~kg} / \mathrm{m}^{3}$ \\
\hline Reservoir Temperature (T) & 246 & ${ }^{0} \mathrm{~F}$ \\
\hline Reservoir Pressure $\left(p_{r}\right)$ & 3000 & Psi \\
\hline Fracturing Pressure $\left(p_{f}\right)$ & 4300 & Psi \\
\hline \multicolumn{3}{|c|}{ Acid Properties } \\
\hline Density $\left(\rho_{\text {Acid }}\right)$ & 1000 & $\mathrm{~kg} / \mathrm{m}^{3}$ \\
\hline Acid initial concentration $\left(c_{i}\right)$ & $4.4(16 \%)$ & moles $/ \mathrm{dm}^{3}$ \\
\hline Spurt loss $\left(S_{p}\right)$ & 0 & $\mathrm{~m}$ \\
\hline Fraction of acid to react before leaking off $\left(f_{r}\right)$ & 0.3 & - \\
\hline Reaction order $\left(n^{\prime}\right)$ & 0.63 & - \\
\hline Reaction rate coefficient $\left(E_{f}\right)$ & 0.3263 & $m^{2} s\left(\frac{k g \text { moles } \mathrm{HCl}}{m^{3} \text { acid solution }}\right)^{n^{\prime}}$ \\
\hline \multicolumn{3}{|c|}{ Parameters of UFD method } \\
\hline Volumetric dissolving power $(X)$ & 0.082 & - \\
\hline Drainage radius $\left(r_{e}\right)$ & 1900 & $\mathrm{Ft}$ \\
\hline Dimensionless horizontal correlation length $\left(\lambda_{\mathrm{D}, \mathrm{x}}\right)$ & 1 & - \\
\hline Dimensionless vertical correlation length $\left(\lambda_{D, \mathrm{Z}}\right)$ & 0.05 & - \\
\hline Dimensionless standard deviation of permeability $\left(\sigma_{\mathrm{D}}\right)$ & 0.4 & - \\
\hline
\end{tabular}




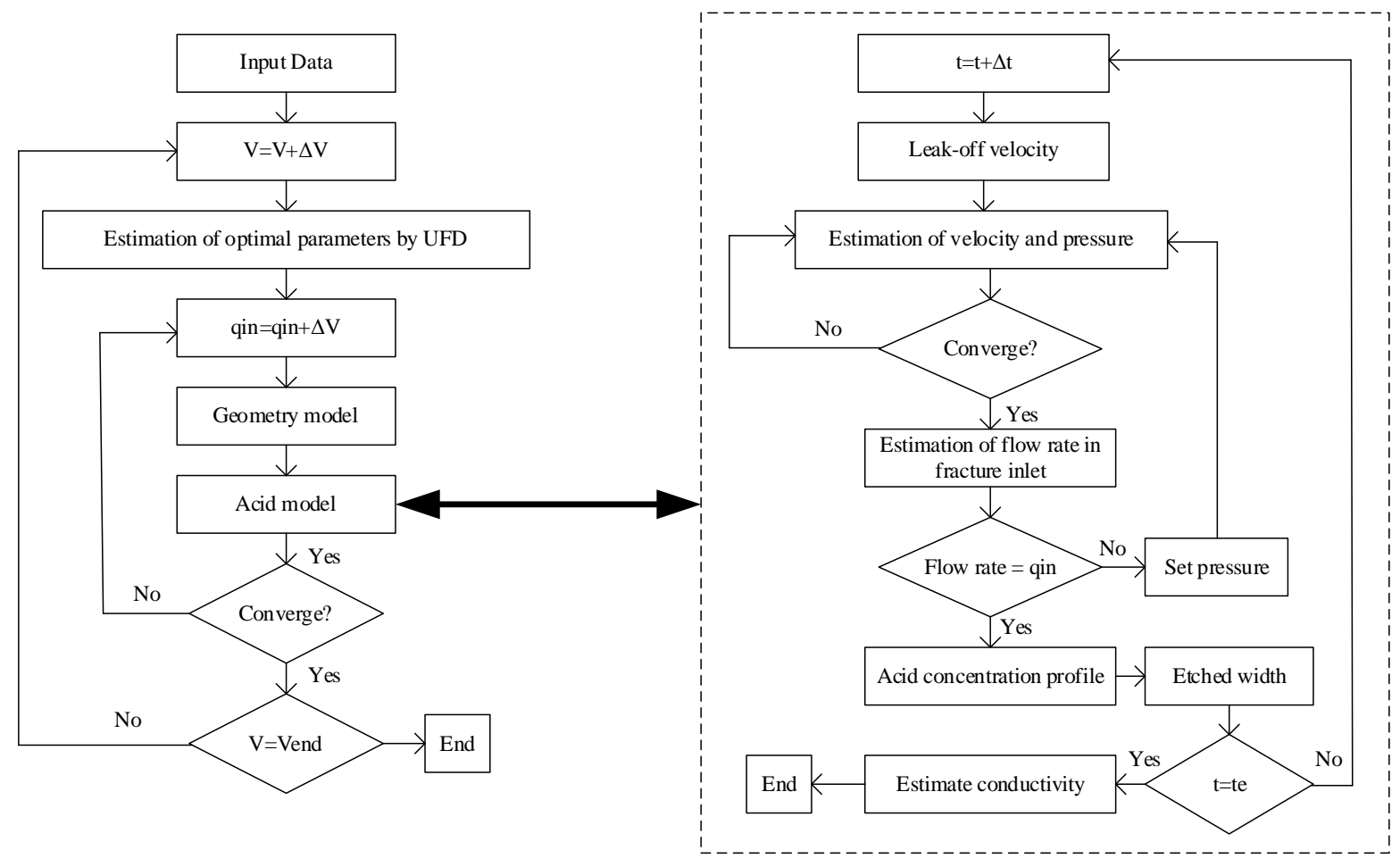

Figure 1. Flowchart of the proposed method.

\subsection{Optimization of the fracture geometry parameters}

UFD method expresses the analytical solution for the optimal dimensionless fracture conductivity to maximize the dimensionless product-ivity index, given a volume of acid. As a result, optimum acid fracture parameters are obtained during the following steps:

- For a specific acid volume and an initial guess for final $x_{\text {opt }}\left(x_{\text {old }}\right)$, the average ideal fracture width is as[4] :

$$
\overline{w_{l}}=\frac{x V_{\text {acid }}}{2(1-\emptyset) x_{\text {old }} h_{f}}
$$

where $\varnothing$ is porosity, $x_{\text {old }}$ is initial guess optimal fracture half-length, $h_{f}$ is the fracture height and equal with net pay of formation. Also, $V_{\text {acid }}$ is injected acid volume, and $X$ is volumetric dissolving power.

- The average ideal fracture width is used to calculate the fracture conductivity. The most recently developed acid fracture conductivity correlation uses geostatistical parameters in the $C_{1}$ and $C_{2}$ coefficients [28] (equation (3)). In this method, the effect of the spatial behavior of the formation's permeability and elastic properties are considered in the calculations. The importance of the acid-etched width to the predicted conductivity is demonstrated in these correlations, where the conductivity is approximately proportional to $\bar{w}_{l}^{2.5}$. It is important therefore that the acid-etched width be accurately determined to understand the conductivity resultant from a particular treatment design.

$$
k_{f}=C_{1} \exp \left(-C_{2} \sigma_{c}\right)
$$




$$
\begin{gathered}
C_{1}=4.48 \times 10^{9}\left[0.1756\left(\operatorname{erf}\left(0.8 \sigma_{D}\right)\right)^{3}{\overline{w_{l}}}^{2.49}\right] \times[1+ \\
\left(1.82 \operatorname{erf}\left(3.25\left(\lambda_{D, x}-0.12\right)\right)-1.31 \operatorname{erf}\left(6 . 7 1 \left(\lambda_{D, z}-\right.\right.\right. \\
\left.0.03))) \sqrt{\exp \left(\sigma_{D}\right)-1}\right] \times\left[0.22\left(\lambda_{D, x} \sigma_{D}\right)^{2.8}+0.01\left(\left(1-\lambda_{D, z}\right) \sigma_{D}\right)^{0.4}\right]^{0.52} \\
C_{2}=\left[14.9-3.78 \ln \left(\sigma_{D}\right)-6.81 \ln (E)\right] \times 10^{-4}
\end{gathered}
$$

where $\lambda_{D, x}$ is dimensionless horizontal correlation length, $\lambda_{D, z}$ is dimensionless vertical correlation length, and $\sigma_{D}$ is the dimensionless standard deviation of permeability. $\sigma_{c}$ is closure stress, $E$ Young's modulus and $\overline{w_{l}}$ is the calculated average ideal fracture width in the previous step. The phrase erf refers to the error function that is given in the model.

- $\quad$ After that, the proppant number for acid fracturing is determined as reported in[29]. An equivalent proppant number was used for calculating the optimum dimensionless fracture conductivity.

$$
\begin{gathered}
N_{A}=\frac{2 k_{f} V_{f}}{k V_{r}} \\
C_{F D \_o p t}=\left\{\begin{array}{c}
1.6 \\
1.6+\exp \left[\frac{-0.583+1.48 \operatorname{Ln}\left(N_{A}\right)}{1+0.142 \operatorname{Ln}\left(N_{A}\right)}\right] N_{A}<0.1 \\
1.6 \quad N_{A}>10
\end{array} \quad 0.1 \leq N_{A} \leq 10\right.
\end{gathered}
$$

- In this step, the optimum fracture half-length and optimum fracture width are calculated as[29]:

$$
\begin{aligned}
& x_{\text {Opt }}=\left(\frac{k_{f} V_{f}}{2 C_{F D_{-} O p t} k h_{f}}\right)^{0.5} \\
& w_{\text {Opt }}=\left(\frac{C_{F D_{-} O p t} k V_{f}}{2 k_{f} h_{f}}\right)^{0.5}
\end{aligned}
$$

- Finally, the calculated fracture half-length and fracture width from equations (6) and (7) are compared with initial $x_{\text {old }}$ and $\overline{w_{l}}$. This process continues until the estimated values reach a stable condition.

\subsection{Fracture propagation model}

During acid fracturing, the fracture's initial geometry is formed by a mechanical process similar to proppant fracturing. The geometry of the fracturing propagation model is based on the PKN method, and fracture half-length is determined as follows[27]:

$$
x_{f}=\frac{q\left(\bar{w}+2 S_{p}\right)}{4 \pi h_{f} C_{L}^{2}}\left[\exp \left(\bar{\beta}^{2}\right) \operatorname{erfc}(\bar{\beta})+\frac{2 \bar{\beta}}{\pi}-1\right], \bar{\beta}=\frac{2 C_{L} \sqrt{\pi t}}{\bar{w}+2 S_{p}}
$$

Where $q$ is the injected flow rate, $S_{p}$ is spurt loss coefficient, $\bar{\beta}$ is a constant parameter $h_{f}$ is fracture height, $C_{L}$ is the leak-off coefficient, $t$ is the injection time and $\bar{w}$ is averaged fracture width in pad stage that can be calculated as:

Newtonian:

$$
\bar{w}=2.05\left(\frac{\left(1-v^{2}\right) \mu q x_{f}}{E}\right)^{0.25}
$$

Non-Newtonian: 


$$
\begin{aligned}
& \bar{w} \\
& =\frac{\pi}{5} 9.15^{\left(\frac{1}{2 n+2}\right)} 3.98^{\left(\frac{n}{2 n+2}\right)}\left[\frac{1+2.14 n}{n}\right]^{\left(\frac{n}{2 n+2}\right)} K^{\left(\frac{1}{2 n+2}\right)}\left[\frac{\left(1-v^{2}\right) x_{f} q^{n} h_{f}^{(1-n)}}{E}\right]^{\left(\frac{1}{2 n+2}\right)}
\end{aligned}
$$

where $\mu$ is fracture-fluid viscosity, $v$ is the Poisson ratio, $E$ is the Young's modulus, $n$ is power in the power-law model, and $K$ is the consistency index. Also, fracture half-length, averaged fracture width, maximum width, and net pressure are calculated by numerical root-finding methods[27].

\subsection{Acid model}

During acid injection, the fracture width (Figure 2) changes continuously as the rock dissolves. In the acid model, the length and height of the fracture are fixed. At each time step, the fracture propagation model provides the domain for the acid solution. Then, the boundary and initial conditions are applied. Finally, unknown parameters such as fluid velocity components, net pressure, acid concentration, acid-etched width, and fracture conductivity within the fracture domain are estimated.

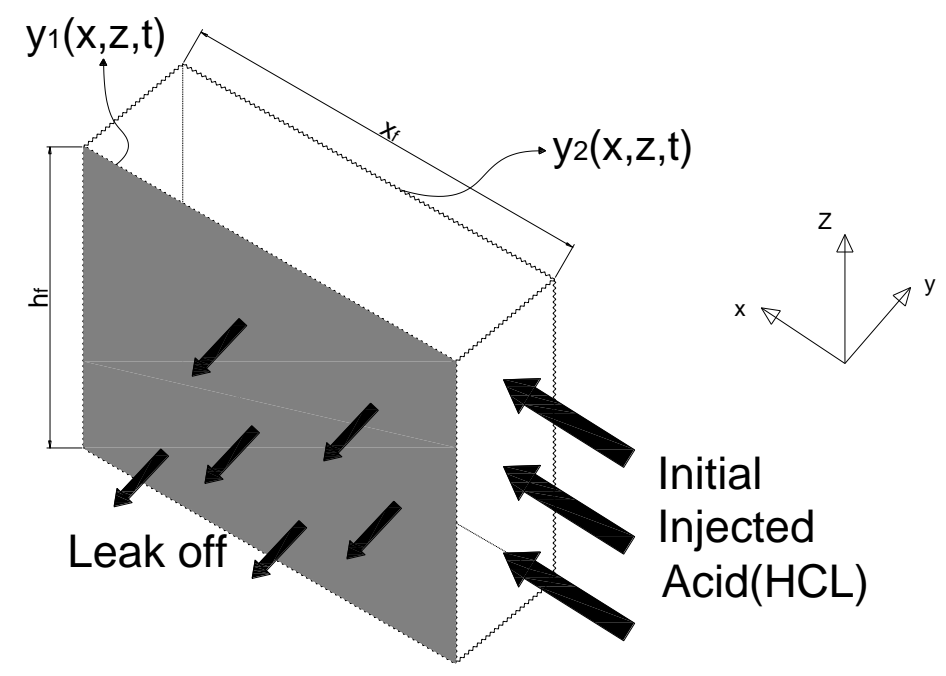

Figure 2. The domain of the acid model.

\subsubsection{Fluid velocity components and pressure}

In order to estimate acid concentration within the fracture, the fluid velocity components should be calculated. Navier-Stokes equations were used for this purpose. The closed-form of the momentum equation is as folwing:

$$
\rho\left\{\frac{\partial v_{i}}{\partial t}+v_{j} \frac{\partial v_{i}}{\partial x_{j}}\right\}+\frac{\partial p}{\partial x_{i}}=\mu \frac{\partial^{2} v_{i}}{\partial x_{j} \partial x_{j}}
$$

Besides, the continuity equation of fluid flows is obtained according to:

$$
\frac{\partial v_{i}}{\partial x_{i}}=0
$$


Where $\rho$ is the fluid density, $p$ is the fluid net pressure, $\mu$ is the fracture-fluid viscosity, and $v_{i}$ are the velocity vector. The geometry created by the acid fracturing has an irregular shape, but the equations (11) and (12) can be used for regular shapes. Therefore, the Crank method can be used[30]. As reported in previous studies, FDM method[31] and SIMPLEM algorithm[32] are employed to solve the velocity and fluid net pressure components within the fracture. Net pressure means the difference pressure between fracture propagation pressure and closure stress.

\subsubsection{Calculate the acid concentration}

The acid concentration profile gives the amount of acid that reaches the surfaces. Acid due to convection and diffusion are transformed to the fracture surfaces, so we consider diffusion and convection in the $\mathrm{y}$-direction. Diffusion in the $\mathrm{x}$ and $\mathrm{z}$ directions is neglected because convection dominates the acid flow in these directions[12]. The mass Continuity equation was used to calculate the acid concentration profile within the fracture.

$$
\frac{\partial C_{D}}{\partial t}+u \frac{\partial C_{D}}{\partial x}+v \frac{\partial C_{D}}{\partial y}+w \frac{\partial C_{D}}{\partial z}=\frac{\partial}{\partial y}\left(D_{e f f} \frac{\partial C_{D}}{\partial y}\right)
$$

Where $D_{\text {eff }}$ is effective acid diffusion coefficient and $C_{D}$ is the dimensionless acid concentration that changes over time along fracture length, height, and width.

\subsubsection{Rocks displacement on the fracture surfaces}

The amount of rock dissolution can be obtained by calculating the acid concentration profile. Acid leak-off and a gravity force gradient transport acid to the walls. The acidetched width can be calculated as follows[31]:

$$
\frac{\partial y}{\partial t}=\frac{\beta M W_{\text {acid }} C_{i}}{\rho_{\text {rock }}(1-\emptyset)}\left(f_{r} v_{L} C_{D}-D_{\text {eff }} \frac{\partial C_{D}}{\partial y}\right)
$$

Where $\rho_{\text {rock }}$ is formation rock density, $\emptyset$ is porosity, $v_{L}$ is leak-off velocity, $C_{i}$ is injected-acid concentration. The type of acid may change with changing gravitational dissolving power $(\beta)$ and the acid's molecular weight $\left(M W_{\text {acid }}\right)$. The part of the acid reacts with the walls before leak-off into the formation; this parameter is expressed by $f_{r}$.

\subsubsection{Boundary condition}

The velocity boundary conditions at the top and bottom of the fracture are such that no slippage occurs.

$$
\left.u\right|_{z=0, H}=\left.v\right|_{z=0, H}=\left.w\right|_{z=0, H}=0
$$

The fluid velocity at the entrance and end of the fracture in both $\mathrm{y}$ and $\mathrm{z}$ directions is such that no slippage occurs.

$$
\left.v\right|_{x=0, L}=\left.w\right|_{x=0, L}=0
$$

At the entrance of the fracture, the fluid flow only in the direction of the $x$-axis. The boundary conditions are a function of the injection flow rate and the flow entrance crosssection.

$$
q=\left.\int_{0}^{h_{f}} \mathrm{dz} \int_{-\mathrm{b} / 2}^{\mathrm{b} / 2} u\right|_{x=0} d y
$$

Fluid velocity boundary conditions in the fracture surfaces are presented as follows:

$$
\begin{gathered}
\left.u\right|_{y=-\mathrm{b} / 2, \mathrm{~b} / 2}=\left.w\right|_{y=-\mathrm{b} / 2, \mathrm{~b} / 2}=0 \\
\left.v\right|_{y=-\mathrm{b} / 2, \mathrm{~b} / 2}=v_{L}(t)
\end{gathered}
$$


The fluid velocity component in both $x$ and $z$ directions on the fracture surfaces ($\mathrm{b} / 2$ and $\mathrm{b} / 2$ ) is zero. The fluid velocity component along the $y$ axis located in the fracture surfaces is based on fluid leak-off velocity changes [33]. The leak-off rate depends on a leak-off coefficient and is proportional to the treatment time's root inverse [6].

$$
v_{L}(t)=\frac{C_{L}}{\sqrt{t-t_{0}}}
$$

Where $C_{L}$ is the leakoff coefficient and estimated by method as present in the next step[6].The exposure time $t-t_{0}$ at a particular location on the fracture is the time elapsed between the current time $t$ and $t_{0}$ at which the fracture tip arrived at that location. The initial concentration of acid is zero everywhere in the fracture.

$$
\left.C\right|_{t=0}=0
$$

The acid concentration at the fracture inlet is equal to the initial amount of acid.

$$
\left.C\right|_{x=0}=C_{i}
$$

The acid reaction at fracture surfaces is a function of acid concentration[1,34]. The boundary conditions of the acid concentration were applied on the fracture surfaces as:

$$
D_{e f f} C_{i} \frac{\partial C_{D}}{\partial y}=E_{f}\left(C_{i} C_{D}-C_{e q m}\right)^{n^{\prime}}(1-\emptyset)
$$

Where $E_{f}$ is reaction rate coefficient, $n^{\prime}$ is reaction order, and $C_{\text {eqm }}$ is acid equilibrium concentration. The acid reaction at the top and bottom of the fracture is zero.

$$
\frac{\partial C_{D}}{\partial z}=0
$$

\subsection{Leak-off model}

The leak-off coefficient is a critical parameter[35]. The shape of the fracture and the penetration distance are both affected by this value. The leak-off coefficient is one of the input parameters in the developed algorithm. The leak-off coefficient was calculated as reported in previous studies[6]. The overall fluid leak-off is controlled by the filtration fluid viscosity effect $\left(C_{v}\right)$, wall building effect $\left(C_{w}\right)$, and reservoir fluid viscosity and compressibility effect $\left(C_{c}\right)$. Under the assumption that $C_{w}$ is large when compared with $C_{v}$ or $C_{c}$, the total leak-off coefficient is calculated as [6].

$$
C_{L}=\frac{\frac{-1}{C_{c}}+\sqrt{\frac{1}{C_{c}{ }^{2}}+\frac{4}{C_{v, w h}{ }^{2}}}}{\left(\frac{2}{C_{v, w h}{ }^{2}}\right)}
$$

where $C_{v}$ and $C_{c}$ could be determined from equations (25) and (26), respectively.

$$
\begin{gathered}
C_{v}=\sqrt{\frac{\Delta p \emptyset k}{2 \mu_{a}}} \\
C_{c}=\Delta p \sqrt{\frac{\emptyset k c_{t}}{\pi \mu_{\text {oil }}}}
\end{gathered}
$$

where $\Delta p$ is pressure difference between fracture and formation, $\emptyset$ is rock porosity, $k$ is formation permeability, $\mu_{O i l}$ is the oil viscosity, $c_{t}$ is total compressibility, $\mu_{a}$ is acid viscosity. The viscous fluid-loss coefficient with wormholing $\left(C_{v, w h}\right)$ is related to the usual viscous fluid-loss coefficient without wormholes $\left(C_{v}\right)$ by equation $(27)$. 


$$
C_{v, w h}=C_{v} \sqrt{\frac{Q_{i b t}}{Q_{i b t}-1}}
$$

where, $Q_{i b t}$ is number of PV's injected at wormhole breakthrough.

\section{Acid model validation}

The acid model was compared with the Schechter analytical method [4]. Also, the Terrill (1965) method was used for a specific condition to estimate dimensionless acid concentration along the fracture half-length. The convection/diffusion equation for a steadystate condition and zero acid concentration at the fracture walls can be calculated as follows [36].

$$
\frac{\bar{c}}{C_{i}}=\sum_{m=0}^{\infty} G_{m}\left(1-\frac{x}{x_{f}}\right)^{2 \lambda_{m}^{2} / 3 N_{P e}}
$$

where, $\bar{c}$ is mean acid concentration, $C_{i}$ initial acid concentration, $\lambda_{m}$ are eigenvalues, and $G_{m}$ are constants. The first five terms in the equation (28) for realistic values of Reynolds number $\left(0.001<N_{R e^{*}}<1\right)$ and Peclet number $\left(N_{P e}<8\right)$ are presented in previous study and $\lambda_{m}$ and $G_{m}$ are calculated as follows [4].

$$
\begin{aligned}
& \lambda_{m}=\sum_{i=0}^{3} g_{i, m} N_{P e}{ }^{i}+\sum_{i=1}^{2} h_{i, m} N_{R e^{*}}{ }^{i} \\
& G_{m}=\sum_{i=0}^{3} \bar{g}_{i, m} N_{P e}{ }^{i}+\sum_{i=1}^{2} \bar{h}_{i, m} N_{R e^{*}}{ }^{i}
\end{aligned}
$$

where, values $g_{i, m}, h_{i, m}, \bar{g}_{i, m}$, and $\bar{h}_{i, m}$ are given in Table 2 [4]. The dimensionless acid concentration versus dimensionless fracture half-length was estimated at different Peclet numbers by the numerical and analytical solutions (Figure 3).

Table 2. Constant coefficients for equations (29) and (30) to calculate $\boldsymbol{\lambda}_{\boldsymbol{m}}$ and $\boldsymbol{G}_{\boldsymbol{m}}$ [4].

\begin{tabular}{ccccccc}
\hline$m$ & $g_{0, m} \times 10^{0}$ & $g_{1, m} \times 10^{-1}$ & $g_{2, m} \times 10^{-3}$ & $g_{3, m} \times 10^{-4}$ & $h_{1, m} \times 10^{-3}$ & $h_{2, m} \times 10^{-3}$ \\
\hline 0 & 1.68231 & -2.26693 & 6.7544 & -1.8408 & 6.7593 & -4.6274 \\
1 & 5.67053 & -0.696 & 17.2931 & -2.9304 & 1.0032 & -3.4376 \\
2 & 9.66842 & -0.39587 & 10.7745 & -0.5564 & -5.7028 & -0.4705 \\
3 & 13.66772 & -0.27662 & 7.9375 & -0.1358 & -9.15 & -0.5668 \\
4 & 17.6674 & -0.21305 & 6.34331 & -0.0373 & -12.4496 & -0.71196 \\
\hline$m$ & $\bar{g}_{0, m} \times 10^{-1}$ & $\bar{g}_{1, m} \times 10^{-4}$ & $\bar{g}_{2, m} \times 10^{-4}$ & $\bar{g}_{3, m} \times 10^{-5}$ & $\bar{h}_{1, m} \times 10^{-4}$ & $\bar{h}_{2, m} \times 10^{-4}$ \\
\hline 0 & 9.10378 & -2.38279 & 14.9298 & -8.97017 & -7.08188 & -1.18392 \\
1 & 0.53126 & 1.88909 & -12.5375 & 8.13482 & 4.01538 & 0.35148 \\
2 & 0.15272 & 0.39035 & -1.6607 & 0.68079 & 1.0394 & 0.5154 \\
3 & 0.06807 & 0.0733 & -0.4172 & 0.11131 & 0.58639 & 0.14123 \\
4 & 0.03737 & 0.01901 & -0.1503 & 0.02756 & 0.35277 & 0.05623 \\
\hline
\end{tabular}




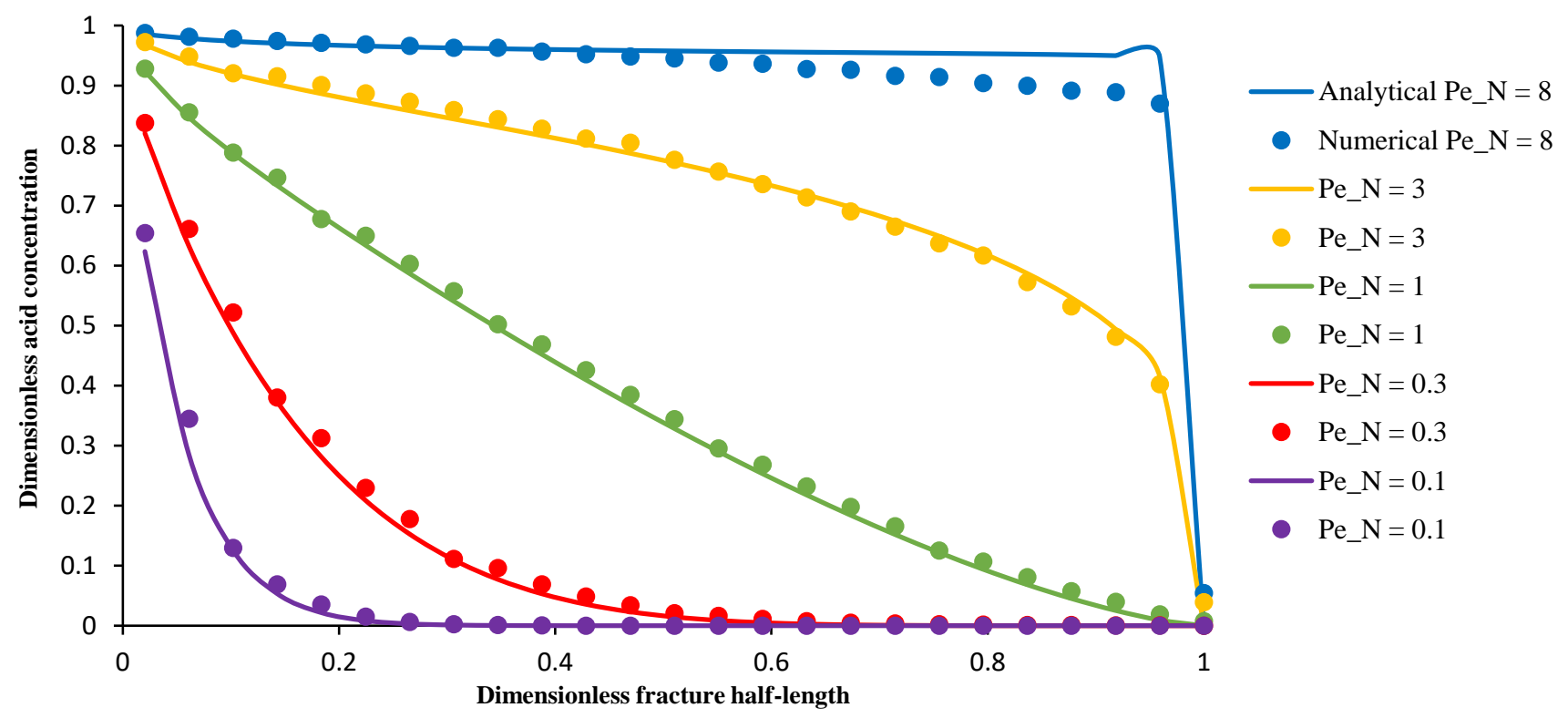

Figure 3. Acid concentration changing along the fracture at different Peclet numbers. Comparison between model and Terrill,1965 method [36].

\section{Model establishment}

Optimization of the acid fracturing treatment requires many simulations. Since it is impossible to provide all the simulations, this section shows the model results for a particular case. A volume of $400 \mathrm{bbl}$ of hydrochloric acid with a $10 \mathrm{bbl} / \mathrm{min}$ flow rate was selected, as its characteristics are given in Table 1. This information used is based on data from an oil well in Iran. This well is one of the wells in the Mansouri field located in the southwest of Iran (Figure 4). The case study reservoir is Bangestan that the lithology of which is mostly limestone (about $98 \%$ ).

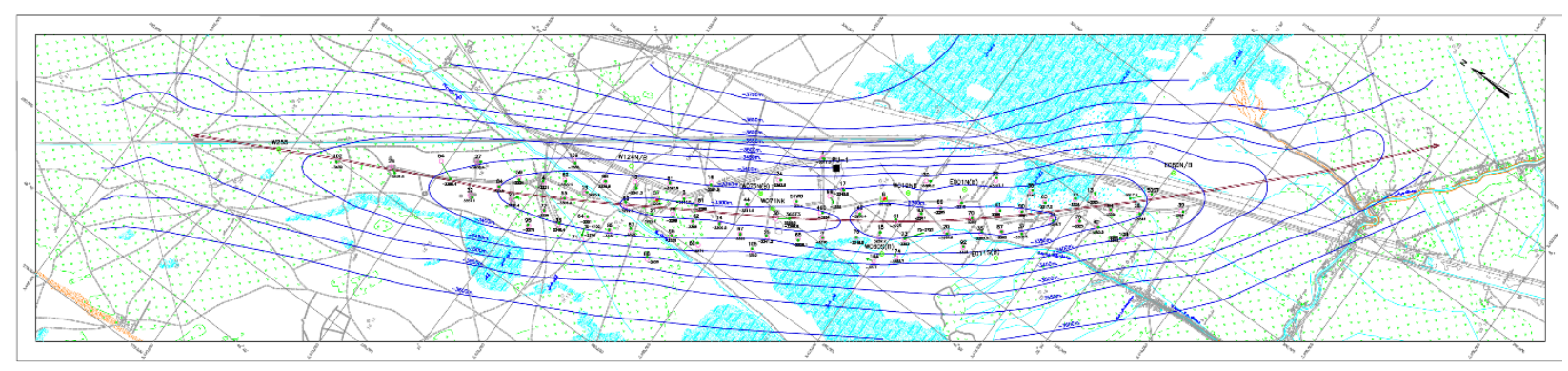

Figure 4. Wells location in the Mansouri field.

Acid concentration profiles are presented in Figure 5. Due to the decrease in fluid velocity along the fracture length, the acid concentration decreased in this direction. Also, acid leak-off into the fracture walls reduces the acid concentration along the fracture width. As shown in Figure 6 and Figure 7, fracture width and conductivity profiles have maximum values in the center and decrease along the fracture length. 


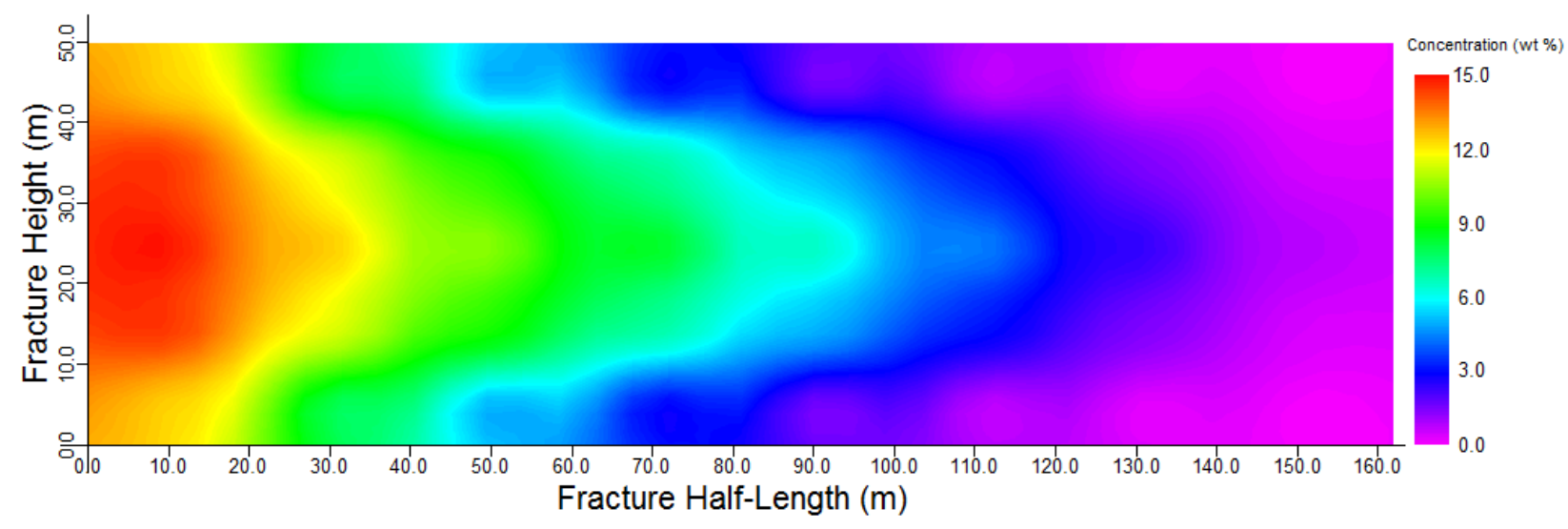

(a) Fracture Half-Length vs. Height

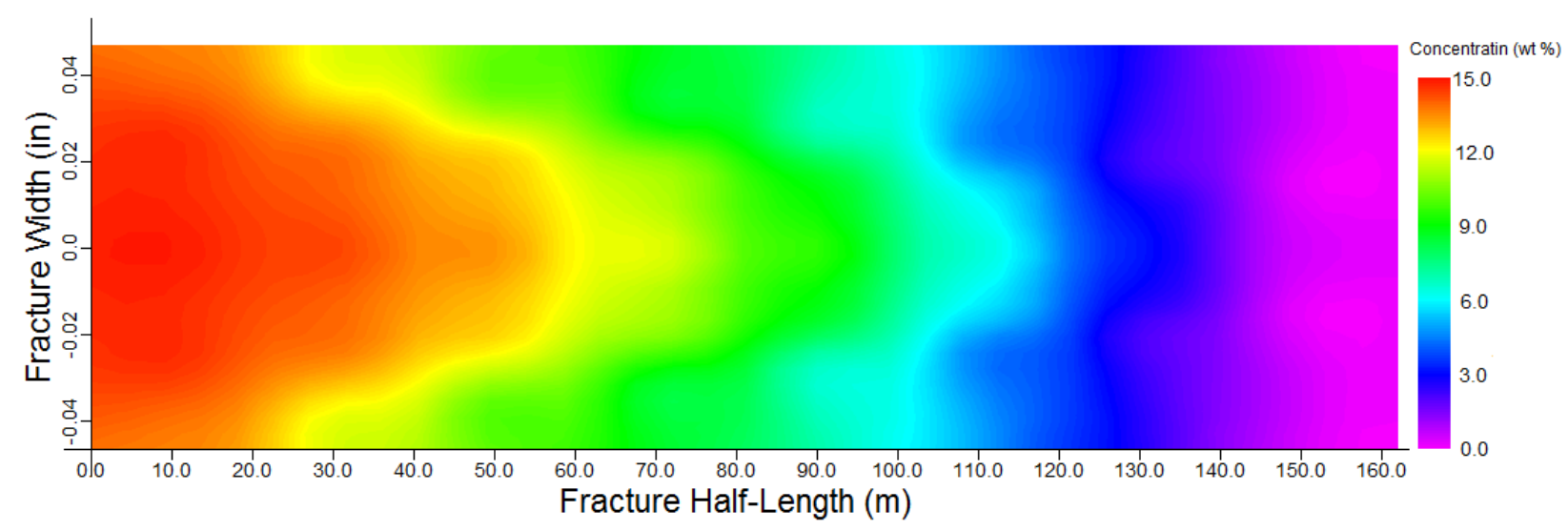

(b) Fracture Half-Length vs. Width

Figure 5. Simulated acid concentration within the fracture domain for a flow rate of $10 \mathrm{bbl} / \mathrm{min}$ and $400 \mathrm{bbl}$ acid volume.

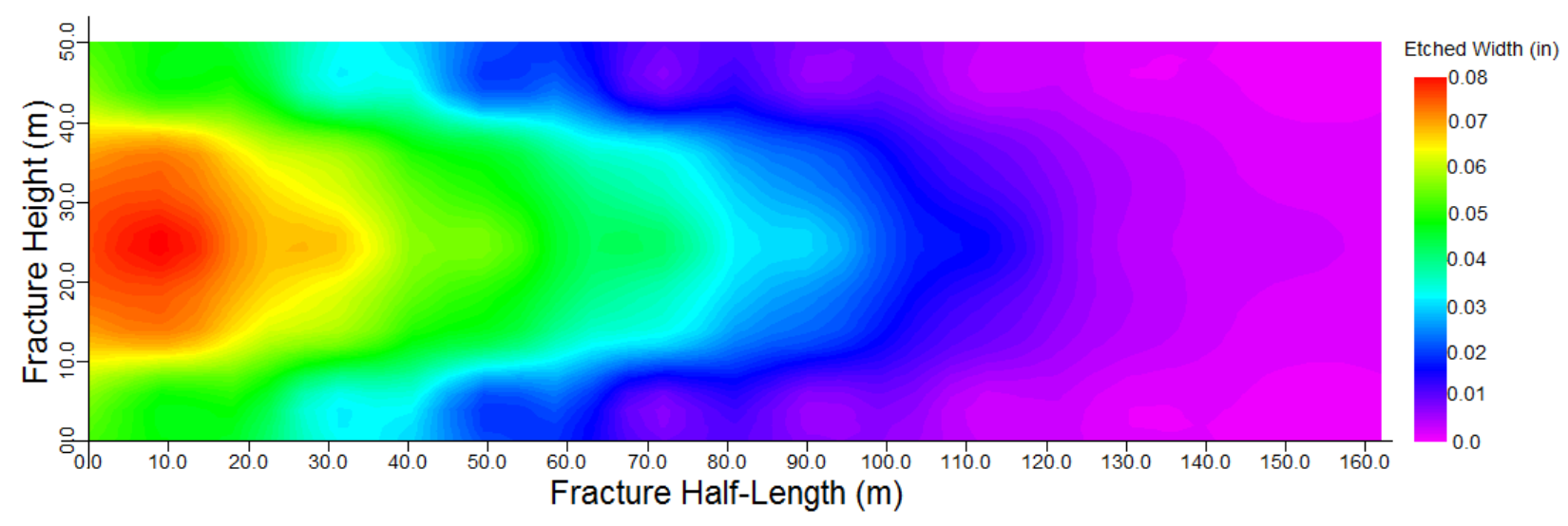

Figure 6. Acid etched-width changes in the length and height of the fracture for a flow rate of $10 \mathrm{bbl} / \mathrm{min}$ and $400 \mathrm{bbl}$ acid volume. 


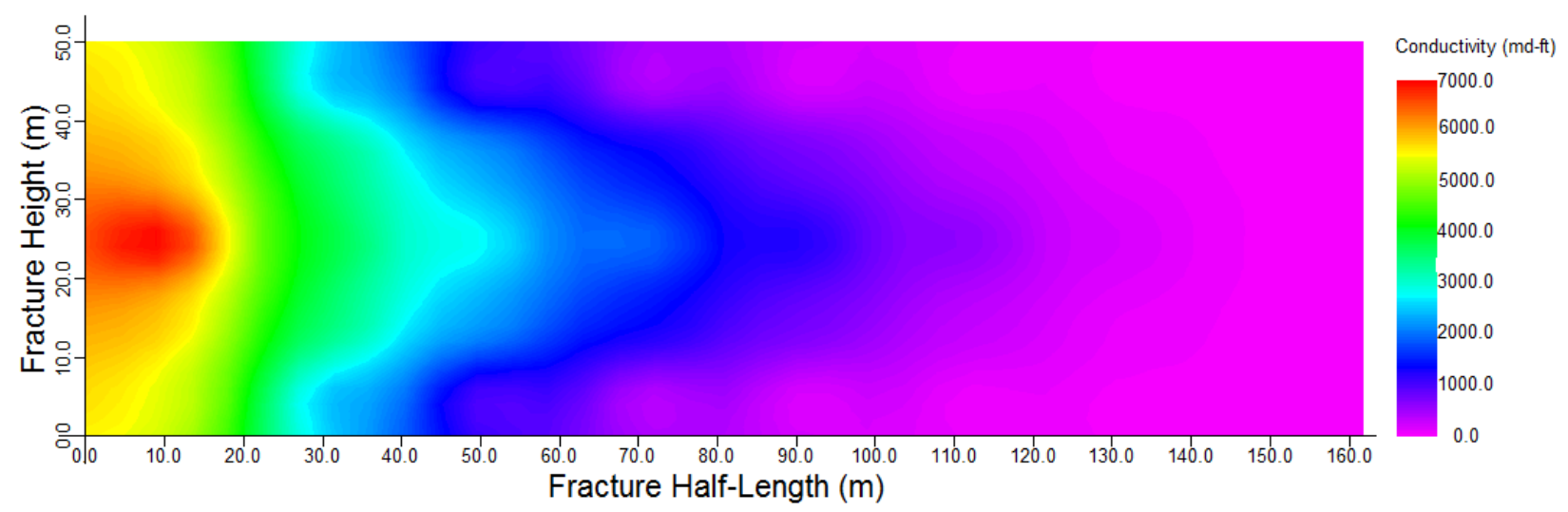

Figure 7. Fracture conductivity changes in the length and height of the fracture for a flow rate of $10 \mathrm{bbl} / \mathrm{min}$ and 400 bbl acid volume.

\section{Optimization of injection parameters}

In this section, injection parameters are optimized based on the proposed method and the input data listed in Table 1 . The acid is assumed to be gelled hydrochloric $(\mathrm{HCl})$ acid. In this study, the initial guess of flow rate $\left(q_{\text {in }}\right.$ in the Figure 1$)$ was considered 1 $\mathrm{bbl} / \mathrm{min}$. Also, the initial acid concentration of 4.4 moles $/ \mathrm{dm}^{3}(16 \%$ acid $\mathrm{HCl})$ was selected. It should be mentioned that in all graphs of this section, the red point on each shape indicates the convergence condition.

\subsection{Effect of flow rate on optimization results}

Figure 8 and Figure 9 show the flow rate changes versus the average acid-etched width and fracture half-length, respectively. When fluid velocity is low, the acid is more likely to diffuse the fracture surfaces, so the width created by the acid will be more significant. Besides, acid can not penetrate through the fracture length, and the maximum effective penetration distance will be small. As the flow rate increases, acid more tends to penetrate along the fracture length. In other words, the convection phenomenon overcomes the acid diffusion into the fracture surfaces. Therefore, the maximum effective acid penetration distance increases and the average fracture width will be small. Therefore, with increasing the flow rate, fracture half-length increase, although average fracture width decrease. This process continues until each parameter reaches the value optimized by the UFD method. The calculated optimal fracture half-length and average fracture width are $738.16 \mathrm{Ft}$ and 0,0133 in, respectively. Figure 10 shows the variation of the computational error with the flow rate. As the flow rate increases, the computational error decreases and reaches its minimum value in the flow rate of $12 \mathrm{bbl} / \mathrm{min}$ (the red point in Figure 10). After that, the computational error value increases because the optimal fracture half-length and average fracture width have deviated from their optimal values. 


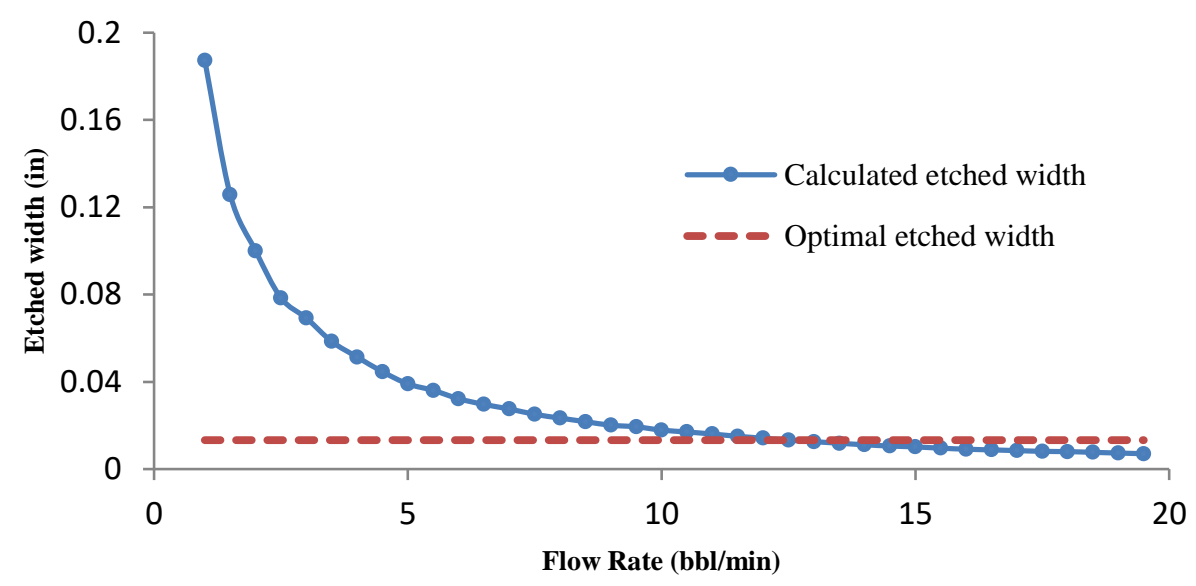

Figure 8. Calculated average acid etched width versus injection flow rate.

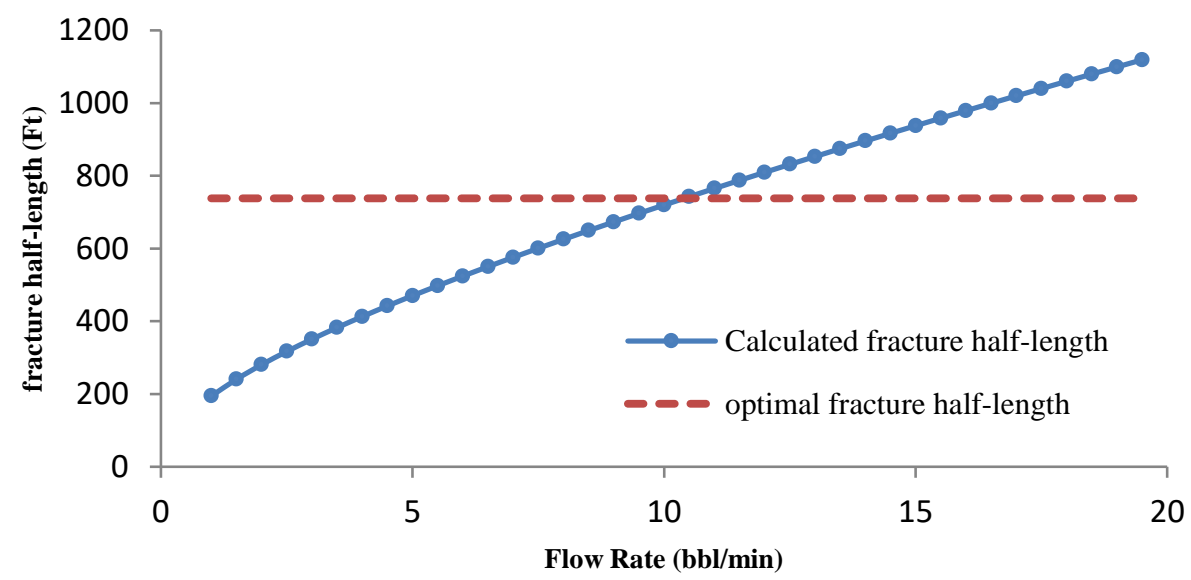

Figure 9. Calculated fracture half-length versus injection flow rate.

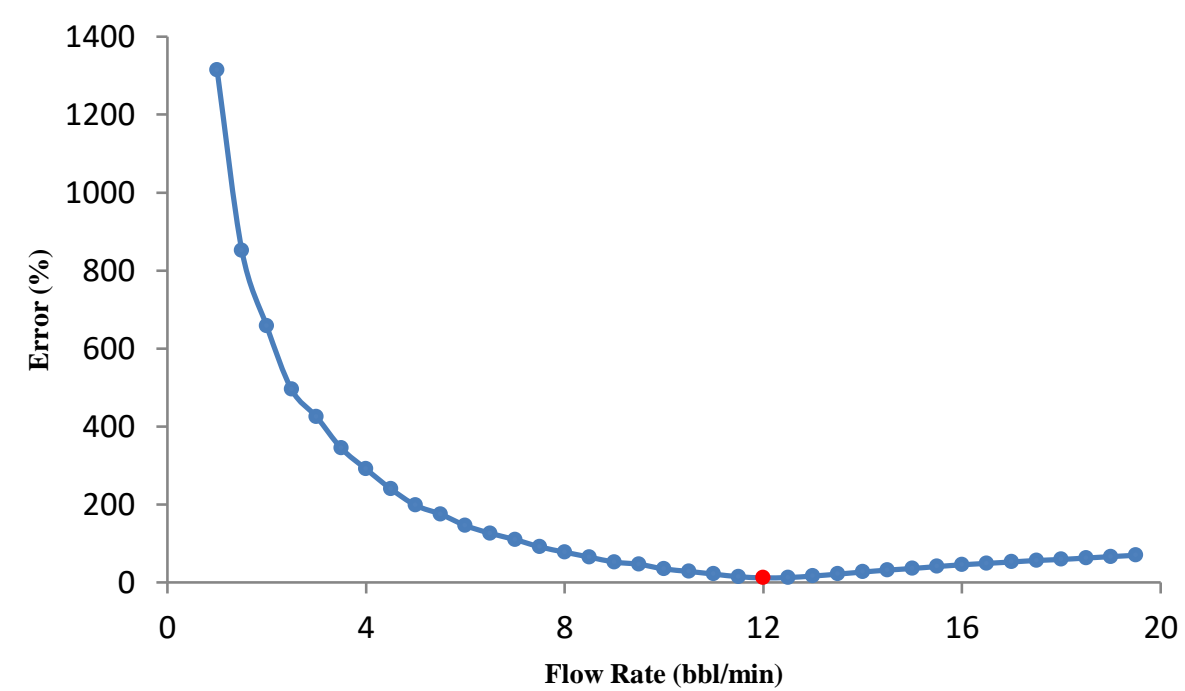

Figure 10. Computational error by changing the injection flow rate for an acid volume of $540 \mathrm{bbl}$. 
Acid volume significantly influences the acid fracturing treatment results. Since the acid volume change causes the optimal fracture geometry parameters and the optimal flow rate will change. Therefore, in this study, the volume was changed for a specific range, and the minimum, maximum acid volume, and the volume difference were selected 50,1500,50 bbl, respectively. The calculations continue until the last volume, and the minimum error is recorded in a specific volume for the following calculations. Minimum error changes versus acid volume graph are presented in Figure 11-a. The calculated error value decreases as the volume increases, and after reaching the minimum error value, the graph slope increases. The error-derived curve versus volume was also used to analyze the accuracy of results. According to Figure 11-b, the error derivative starts with a steep slope and then slowly increases. The error derivative within the red circle in Figure 11-b strikes the zero line for the first time. This collision is equivalent to the minimum error (red dot in Figure 11-a). The volume calculated at this point is $900 \mathrm{bbl}$. Selecting a larger volume not only increases the treatment risk, operating costs will rise significantly. The optimal flow rate for each acid volume was calculated, and the results are shown in Figure 12. If a high acid volume is selected, optimum fracture half-length and average fracture width estimated by the UFD method increase. These conditions can only be achieved at a high flow rate. In general, it has been proven that the optimum flow rate increases with the increase in acid volume [22]. For instance, the flow rate for 900 selected bbl is 15 $\mathrm{bbl} / \mathrm{min}$.

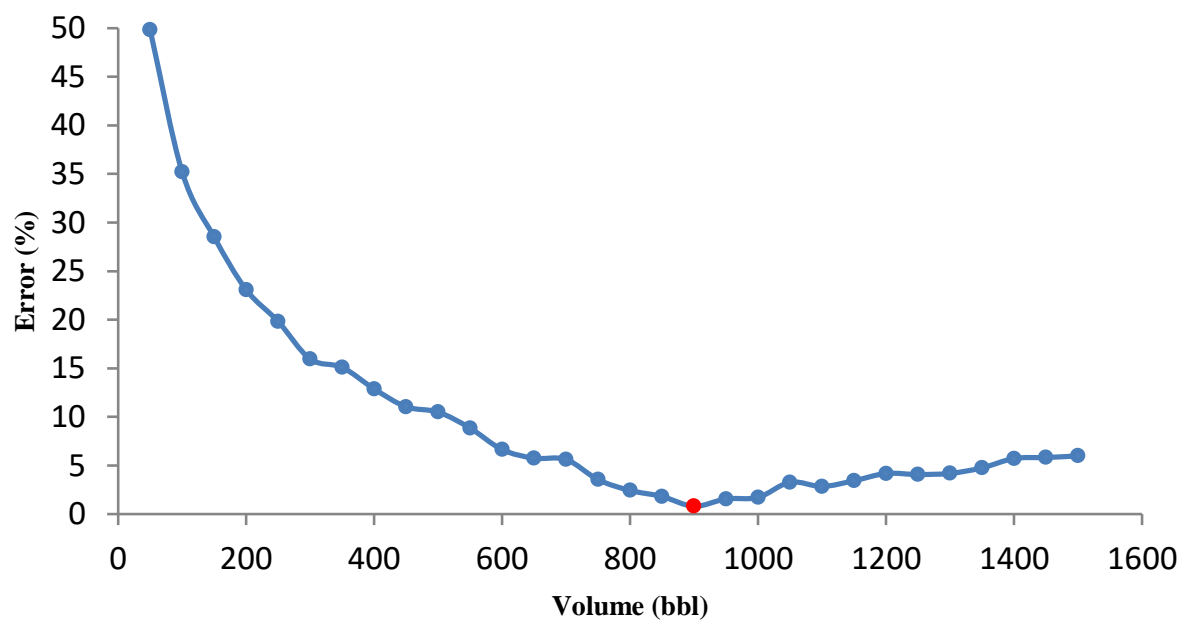

(a) Error vs. Acid volume

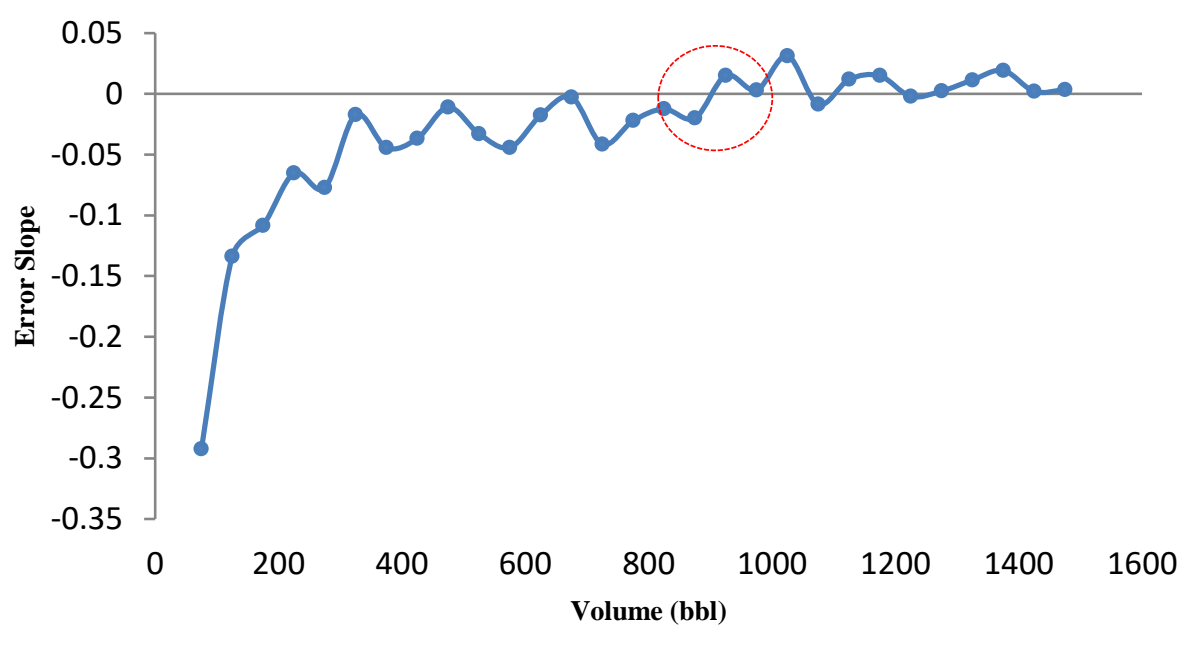

(b) Error slope vs. Acid volume

Figure 11. Minimum computational error for a given volume (a). Error derivative changes versus acid volume (b). 


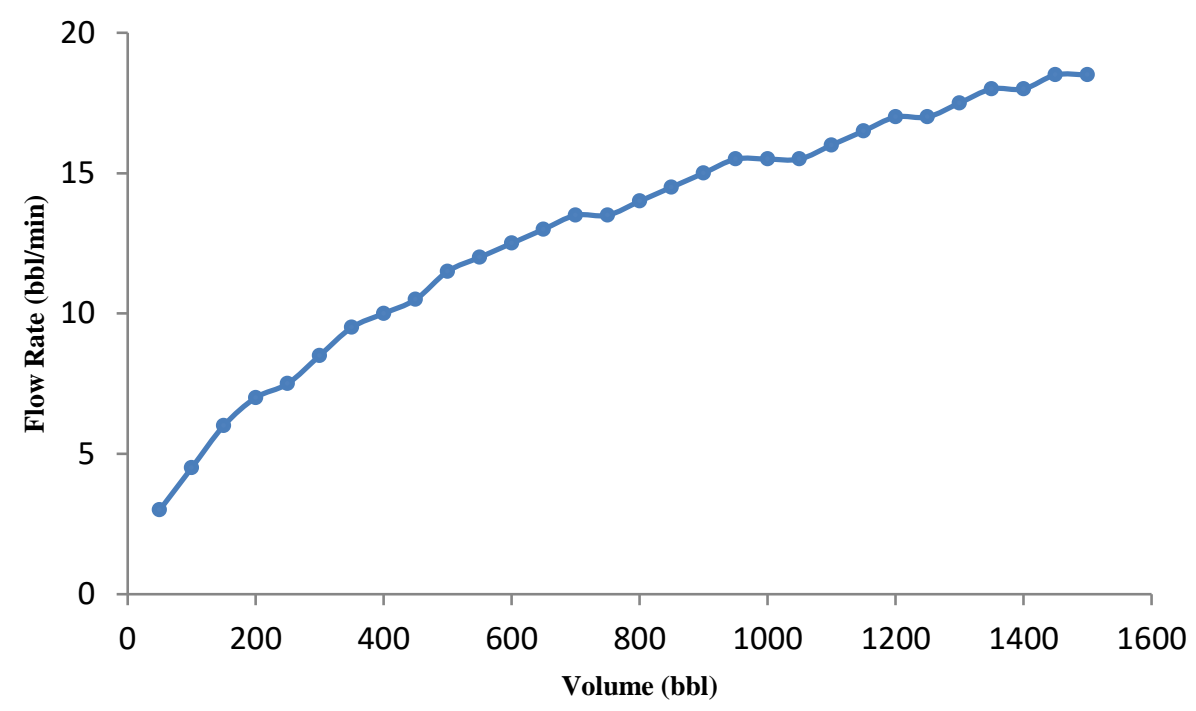

Figure 12. Optimum flow rate changes versus acid volume.

\section{Parametric study}

In this section, the effect of the formation's inherent properties (permeability and elastic properties) and controllable parameters (flow rheology and type and acid percentage) on the optimal rate and volume are investigated. The input data are entered into the model according to Table 1, unless a specific parameter of this table is the purpose of evaluation. In all graphs of this section, the red dot represents optimum conditions.

\subsection{Effect of formation permeability}

The formation permeability has a significant influence on the optimal fracture geometry parameters calculated by the UFD method. The effect of permeability for two samples with values of 0.1 and $0.001 \mathrm{md}$ on the injection flow rate was investigated. It should be mentioned that the considered acid volume is $500 \mathrm{bbl}$. The flow rate- error graph for two samples is presented in Figure 13. It is desirable for low formation permeability to achieve a fracture with a high fracture half-length and small average fracture width. A higher flow rate will be required for the acid to penetrate deep into the fracture. The optimum flow rate for the permeability of 0.001 and $0.1 \mathrm{md}$ was calculated 18 and $11.5 \mathrm{bbl} / \mathrm{min}$, respectively. To investigate the effect of volume on the optimization results, the acid volume was increased to $1000 \mathrm{bbl}$, and the calculations were repeated as the results are shown in Figure 14. If the volume of injected acid increases, the flow rate should be increased to approach the fracture geometry optimal condition. Therefore, the optimum flow rate increases for both samples. However, when permeability is $0.001 \mathrm{md}$, a more flow rate is needed. The optimum flow rates for the permeability of 0.001 and 0.1 md were 21 and 16.5 $\mathrm{bbl} / \mathrm{min}$, respectively. 


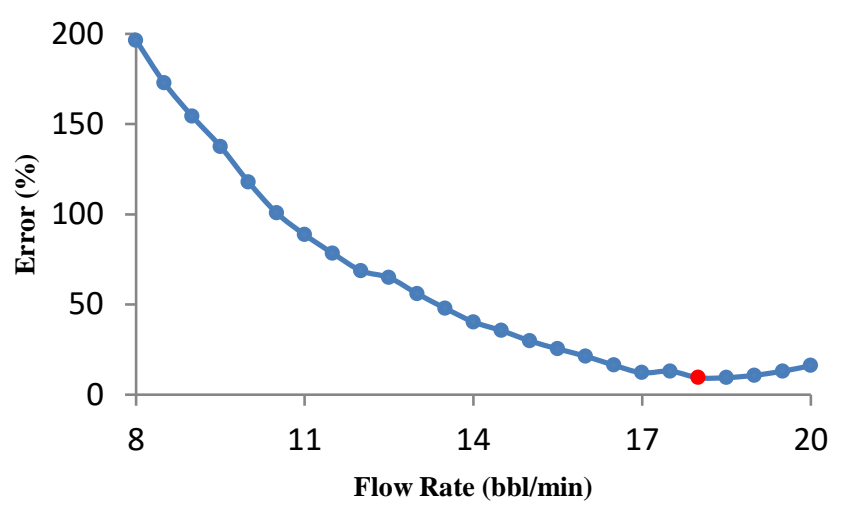

$\mathrm{K}=0.001$

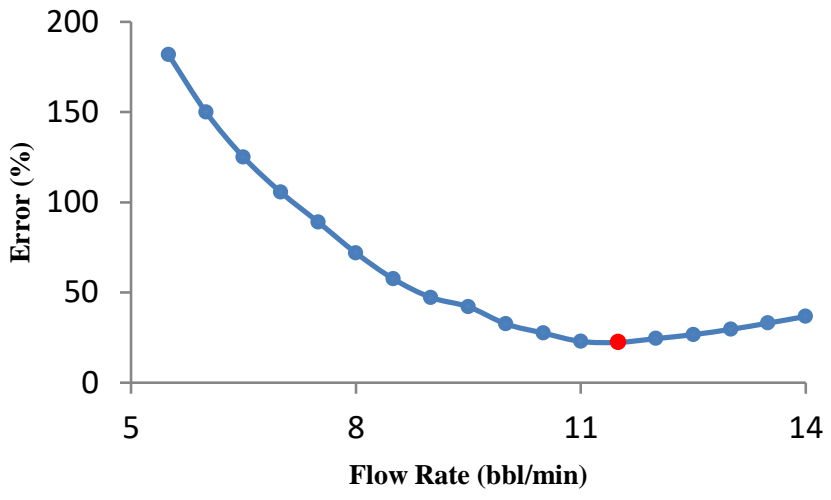

$\mathrm{K}=0.1$

Figure 13. Formation permeability effect on results of injection flow rate optimization for a $500 \mathrm{bbl}$ Acid Volume.

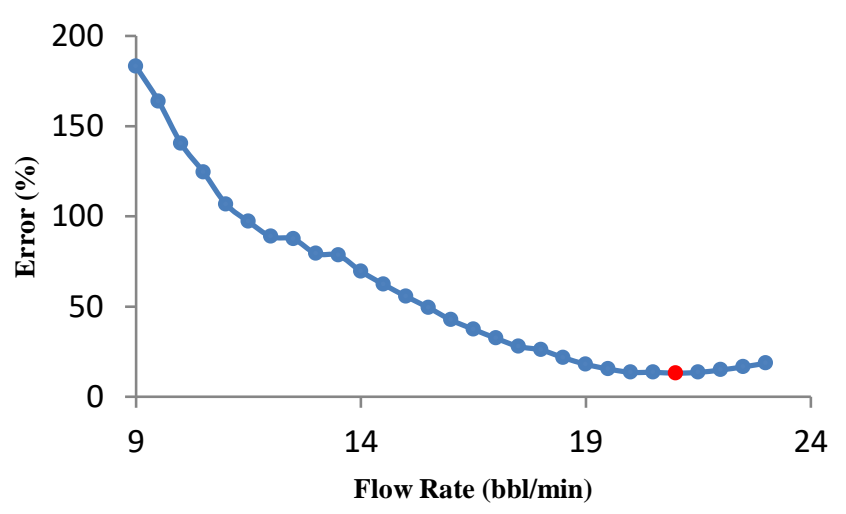

$\mathrm{K}=0.001$

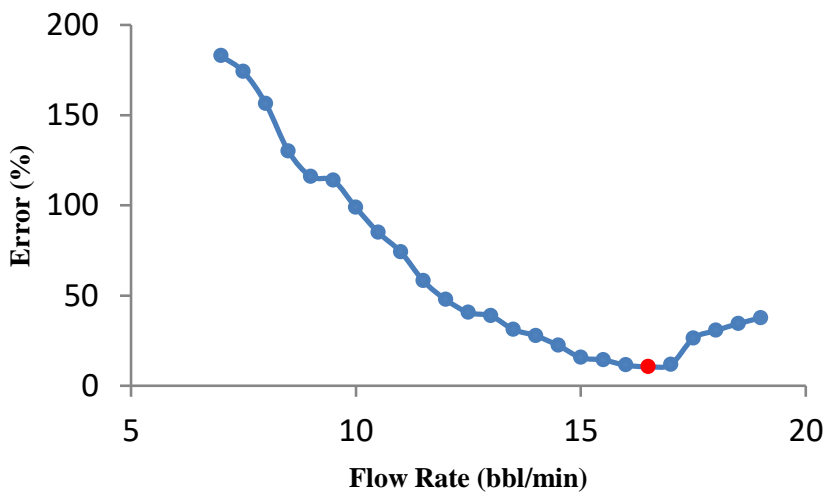

$K=0.1$

Figure 14. Effect of formation permeability on the results of injection flow rate optimization for a 1000 bbl Acid Volume.

\subsection{Effect of Injection Fluid Rheology}

The viscosity of the injected fluid is one of the controllable parameters in hydraulic fracturing. The proper selection of this parameter can reduce costs and improve the results of hydraulic fracturing. The effect of different viscosity on injection flow rate is illustrated in Figure 15. It should be noted that the viscosity refers to the fracture-fluid viscosity as presented in Table 3 [37]. For a low viscosity fluid (14 cp), higher flow rates (about 14 $\mathrm{bbl} / \mathrm{min}$ ) will be required to achieve optimization purposes. In contrast, for high viscosity fluid, a lower flow rate is needed. Fluid leakoff can be controlled in high viscosity values. Therefore, in such conditions, the required fluid flow rate is reduced. 


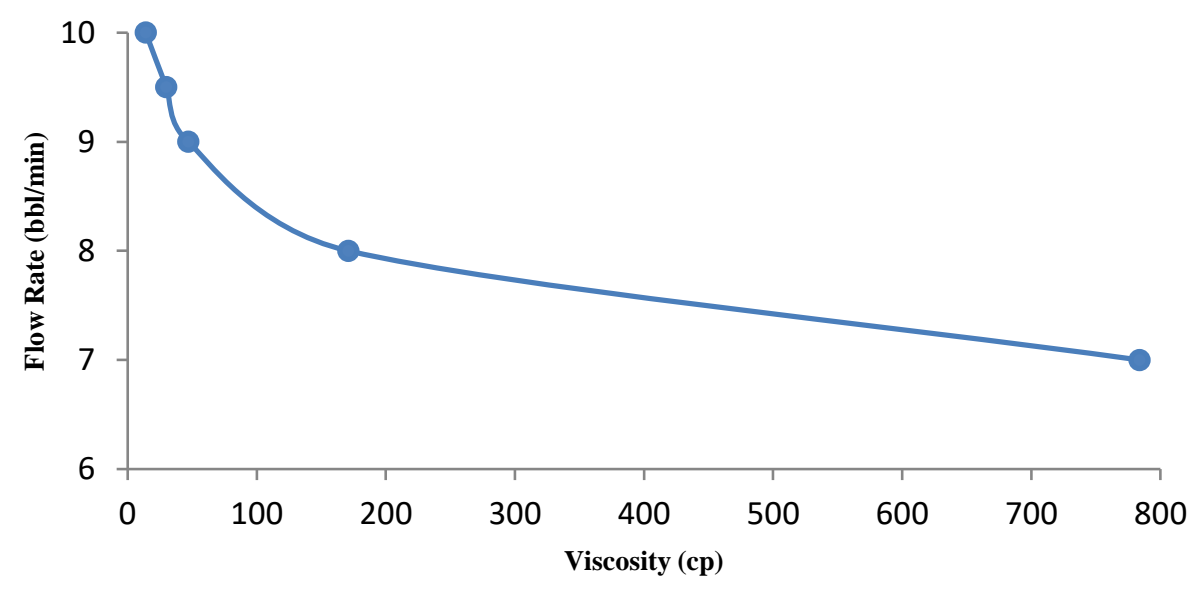

Figure 15. Effect of fluid viscosity on the results of flow rate optimization for a $540 \mathrm{bbl}$ acid volume.

It is noticeable that more acid volume is required for low viscosity fluid to achieve optimal fracture geometry parameters. As shown in Figure 16, the curve slope is significantly steep for low viscosities (before the green dot). A slight increase in the fluid viscosity dramatically reduces the amount of acid required. After this point, the cure slope decreases, which means high viscosity has a negligible effect on reducing the acid volume. In general, increasing the fluid viscosity reduces the volume of acid required and thus reduces the cost of operation. However, increasing the fluid viscosity does not significantly reduce the acid volume. On the other hand, supplying high viscosity fluid has many costs. Therefore, the optimum viscosity and volume of acid are $170 \mathrm{cp}$ and $150 \mathrm{bbl}$, respectively.

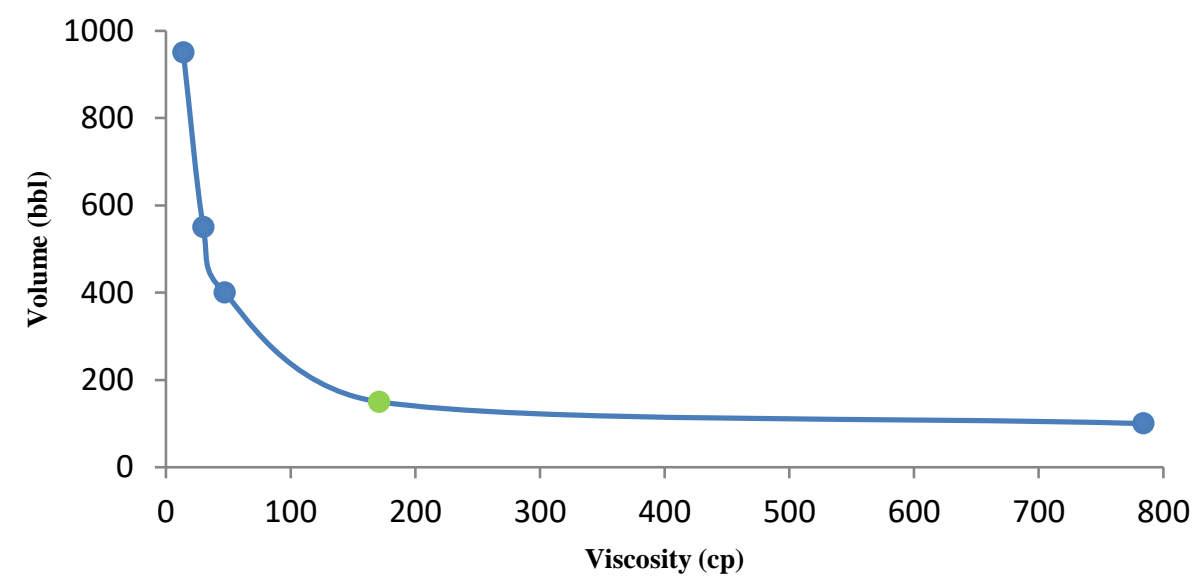

Figure 16. Effect of fluid viscosity on the results of acid volume optimization.

\subsection{Effect of the acid type}

Different types of acid systems in the fracture will behave differently and affect acid optimization results. Straight acid is the simplest type of acid to which no viscosity enhancer or gel has been added. In acid fracturing, more complex acid systems are commonly used to reduce leak-off. In this section, three acid systems were studied, which are listed in Table 3 [37]. In order to investigate the effect of acid type on the flow rate, the acid volume was considered constant and equal to $540 \mathrm{bbl}$. The other parameters are shown in Table 1. The flow rate optimization for the three types of acids is presented in Figure 17. The optimum flow rate for straight acid was calculated to be about $16.5 \mathrm{bbl} / \mathrm{min}$. 
Table 3. Property of three acid systems types studied [37].

\begin{tabular}{ccccc}
\hline Acid types & $\mu_{a} \times 10^{-3}(\mathrm{~kg} / \mathrm{m} . \mathrm{s})$ & $D_{\text {eff }}(\mathrm{cm} 2 / \mathrm{s})$ & $\mathrm{n}$ & $K\left(\right.$ Pa. $\left.{ }^{n}\right)$ \\
\hline Straight & 1 & 0.0000213 & 1.0 & 0.00109 \\
Gelled & 15 & 0.000008 & 0.65 & 0.05 \\
Emulsified & 30 & $2.64 \mathrm{E}-08$ & 0.675 & 0.315 \\
\hline
\end{tabular}

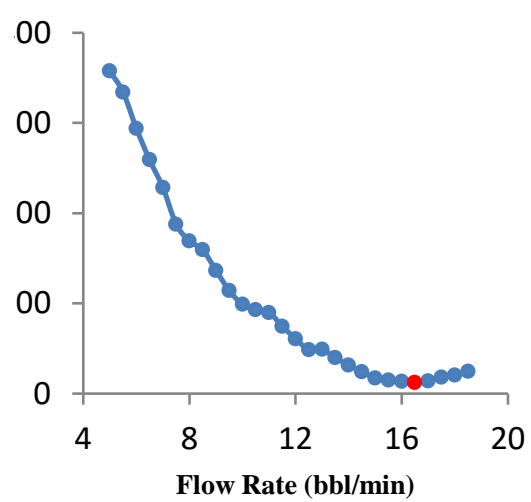

(a) Straight acid

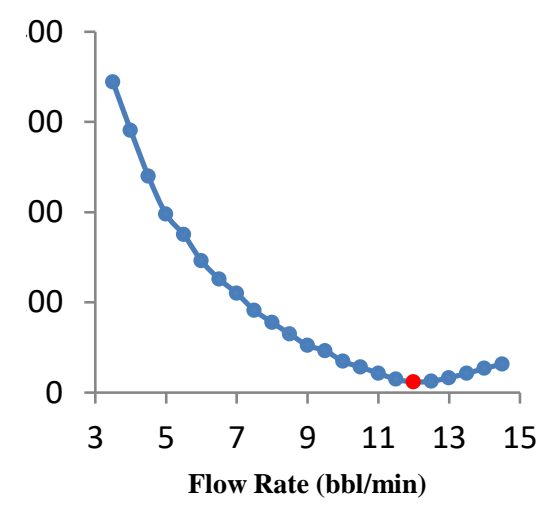

(b) Gelled acid

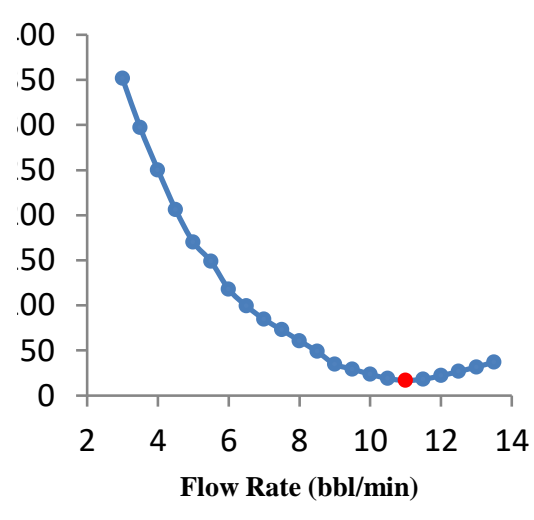

(c) Emulsified acid

Figure 17. Results of flow rate optimization for three acid systems types investigated for a $540 \mathrm{bbl}$ acid.

However, optimum flow rates for gelled and emulsified acids are 12 and $11 \mathrm{bbl} / \mathrm{min}$, respectively. In general, retarded acids have less uncertainty at a lower flow rate. The effect of the flow rate for three acid systems on the fracture half-length and average fracture width is shown in Figure 18. Due to its high diffusion coefficient, the straight acid can be less transported along the fracture length than the other two types of acids. Therefore, a higher flow rate is required to achieve the optimal fracture half-length (Horizontal line in Figure 18-a). On the other hand, straight acid will always create a higher average fracture width for a specified flow rate than the other two types. Therefore, only a high flow rate can bring the average fracture width closure to its optimal value (horizontal line in Figure 18-b). However, for retarded acids, lower flow rates are required to achieve optimal fracture geometry goals.

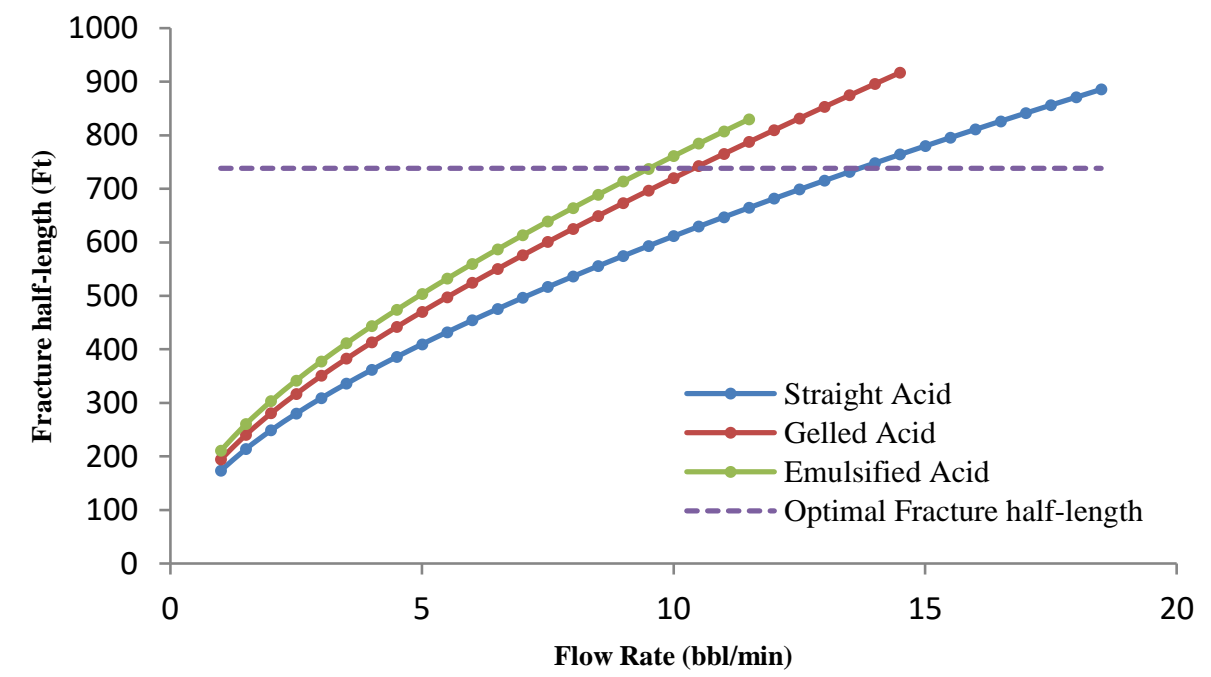

(a) Fracture half-length 


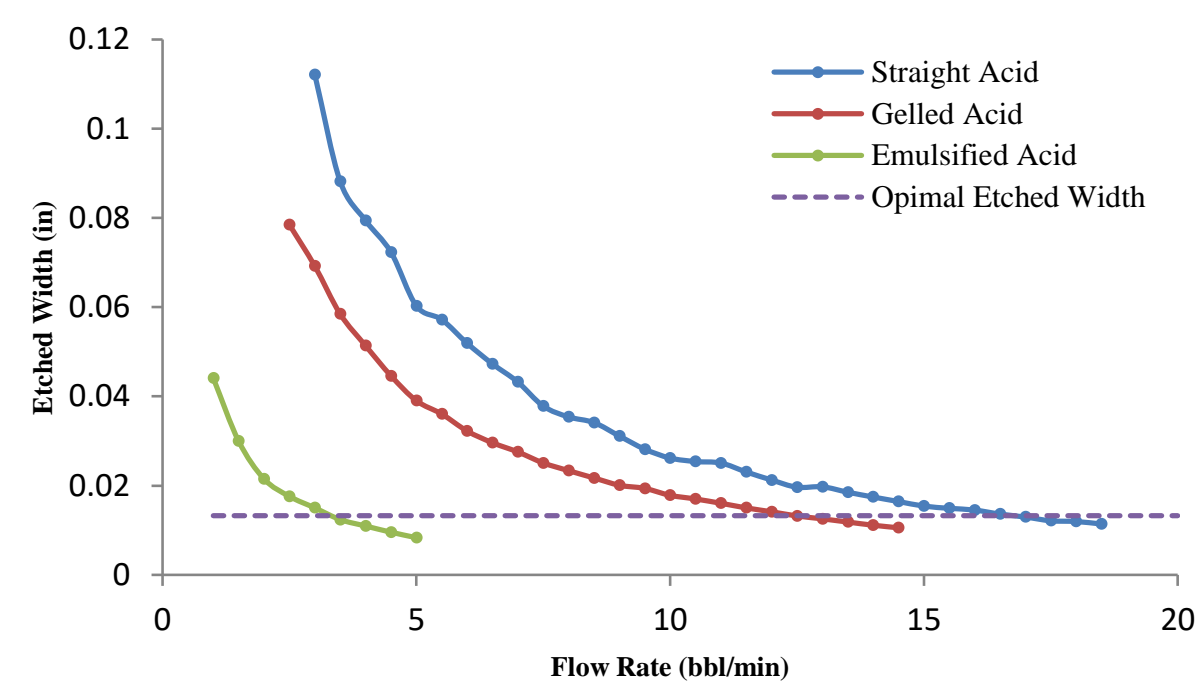

(b) Etched width

Figure 18. Variations of fracture half- length (a) and average etched-width (b) with flow rate for three acid systems types.

Figure 19 illustrates the effect of three types of acid systems on acid volume. First, the error value decreases with increasing acid volume for all three types of acids, and after reaching its minimum value, the calculated error has gradually increased. The calculated optimum volumes for straight acid, gelled, and emulsified are 1050, 1200, and $1600 \mathrm{bbl}$, respectively. For the straight acid, fracture half-length and average fracture width are achieved to the optimum condition of fracture geometry in a smaller volume than the other two acid types by the UFD method. For retarded acids, the optimal conditions are obtained only in a high acid volume, as reported by[22].

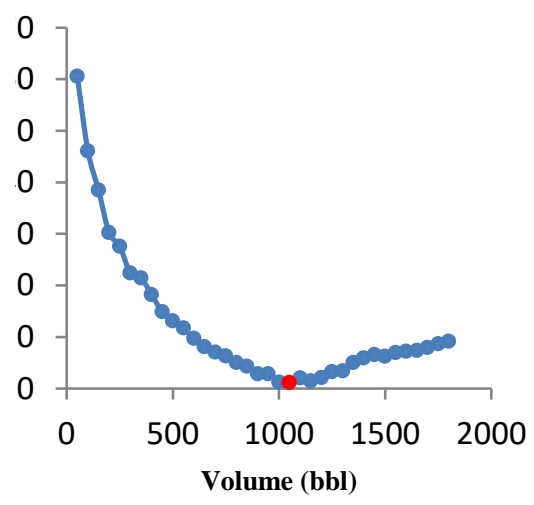

(a) Straight acid

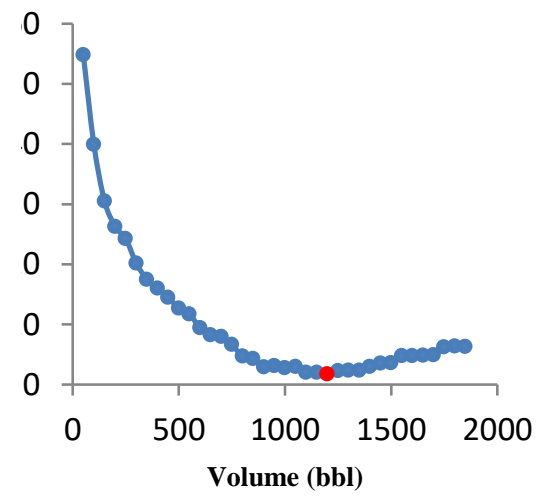

(b) Gelled acid

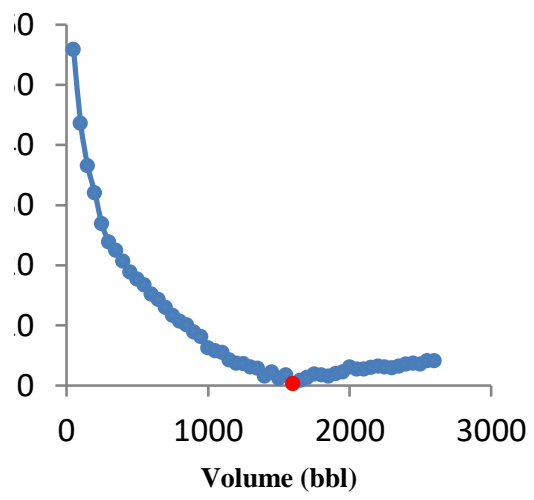

(c) Emulsified acid

Figure 19. Results of acid volume optimization for three acid systems types.

\subsection{Effect of the acid percentage}

In order to investigate the effect of acid percentage on volume and flow rate, $\mathrm{HCl}$ gelled acid with 5, 10, and 15 percentages were used. Figure 20 shows the effect of changes in acid percentage on the optimal flow rate. The optimum flow rate for $5 \%, 10 \%$, and $15 \%$ acid concentrations were calculated to be $5.5,9$, and $11.5 \mathrm{bbl} / \mathrm{min}$, respectively. As the acid percentage increases, the optimum flow rate increases. For a highly acid percentage, the average fracture width increases. In this case, achieving the fracture geometry optimum condition by the UFD method will be possible only at a high flow rate. It should be noted 
that the difference between the estimated optimum flow rate in Figure 10 and Figure 17$\mathrm{b}(12 \mathrm{bbl} / \mathrm{min})$ with Figure $20-\mathrm{c}(11.5 \mathrm{bbl} / \mathrm{min})$ is due to acid concentration decrease from $16 \%$ to $15 \%$.

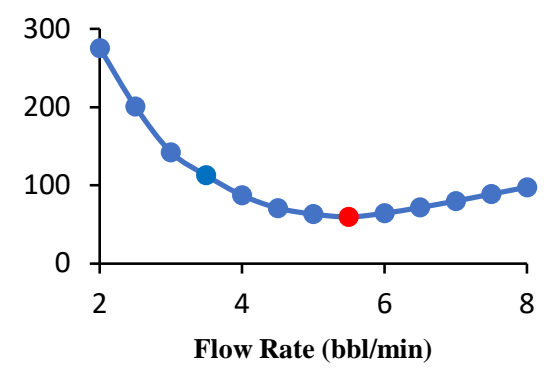

(a) 5 wt $\%$ acid

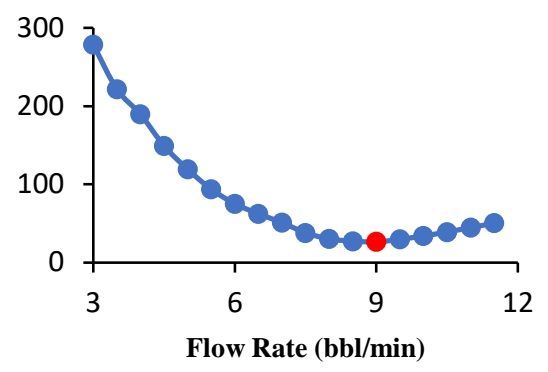

(b) 10 wt $\%$ acid

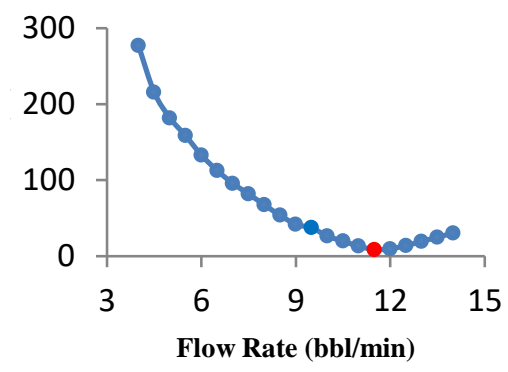

(c) $15 \mathrm{wt} \%$ acid

Figure 20. The effect of acid concentration on the flow rate optimization results for a $540 \mathrm{bbl}$ acid volume.

Also, the effect of acid concentration on the acid volume was investigated, and its results are presented in Figure 21. For acid concentration 5\%, the optimal conditions appear in a low volume (about $100 \mathrm{bbl}$ ). If the acid concentration increases, optimal conditions can only be reached by increasing the acid volume. On the other hand, the acid volume should be increased to achieve the optimal parameters of the fracture geometry with a higher probability (less error). For instance, the optimum volumes for $10 \%$ and $15 \%$ acid concentrations were calculated to be 200 and $900 \mathrm{bbl}$, respectively.

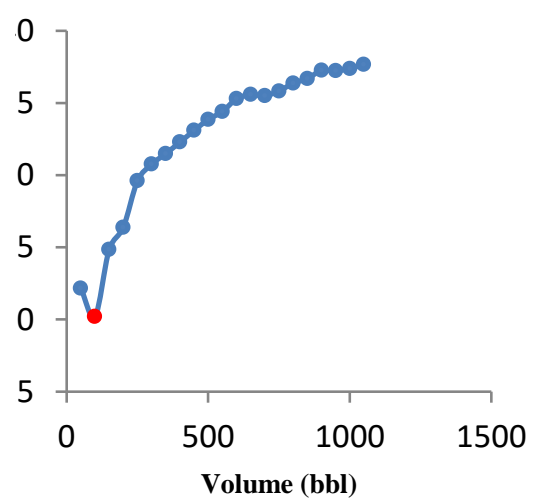

(a) 5 wt $\%$ acid

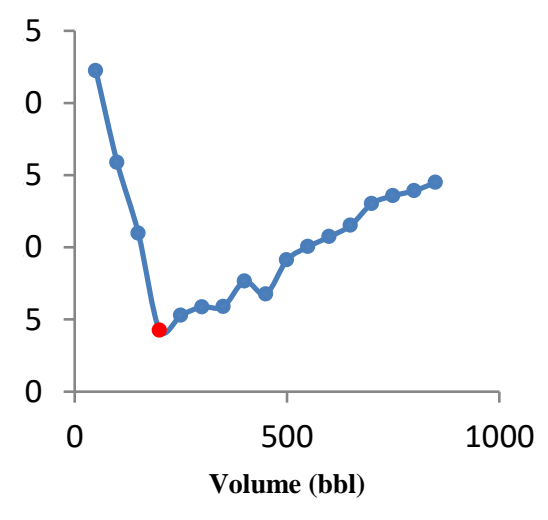

(b) $10 \mathrm{wt} \%$ acid

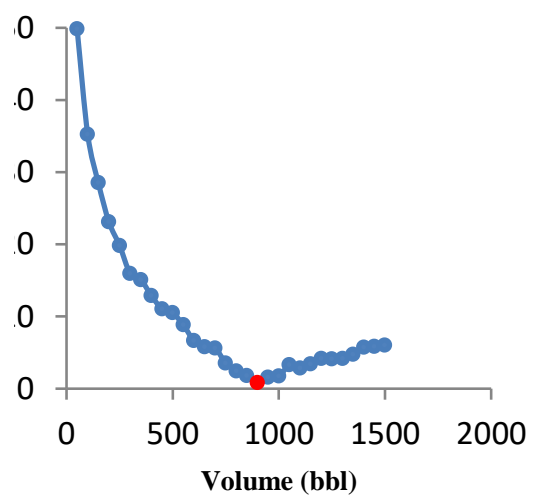

(c) $15 \mathrm{wt} \%$ acid

Figure 21. The effect of acid concentration on acid volume optimization results.

\subsection{Effect of the Young's modulus}

Mechanical properties of the formation have a significant influence on acid fracturing. Particularly, Optimal injection parameters are affected by Young's modulus and the formation closure stress. In this section, a gelled acid was selected with a volume of 540 bbl. The other parameters were kept constant, as listed in Table 1. The effect of the Young's modulus on the fracture geometry optimal condition is shown in Figure 22. Also, the flow rate optimization for different Young's modulus was investigated, and the results are presented in Figure 23. For low Young's modulus, a fracture with a small length and high average width is desirable, and the optimal fracture geometry parameters can be achieved in a low flow rate. However, as Young's modulus increases, the optimal fracture geometry conditions reach a high flow rate. Besides, it was observed that the optimal acid volume decreases by increasing Young's modulus (Figure 24). So optimal fracture geometry parameters are determined in high acid volume for low Young's modulus. 


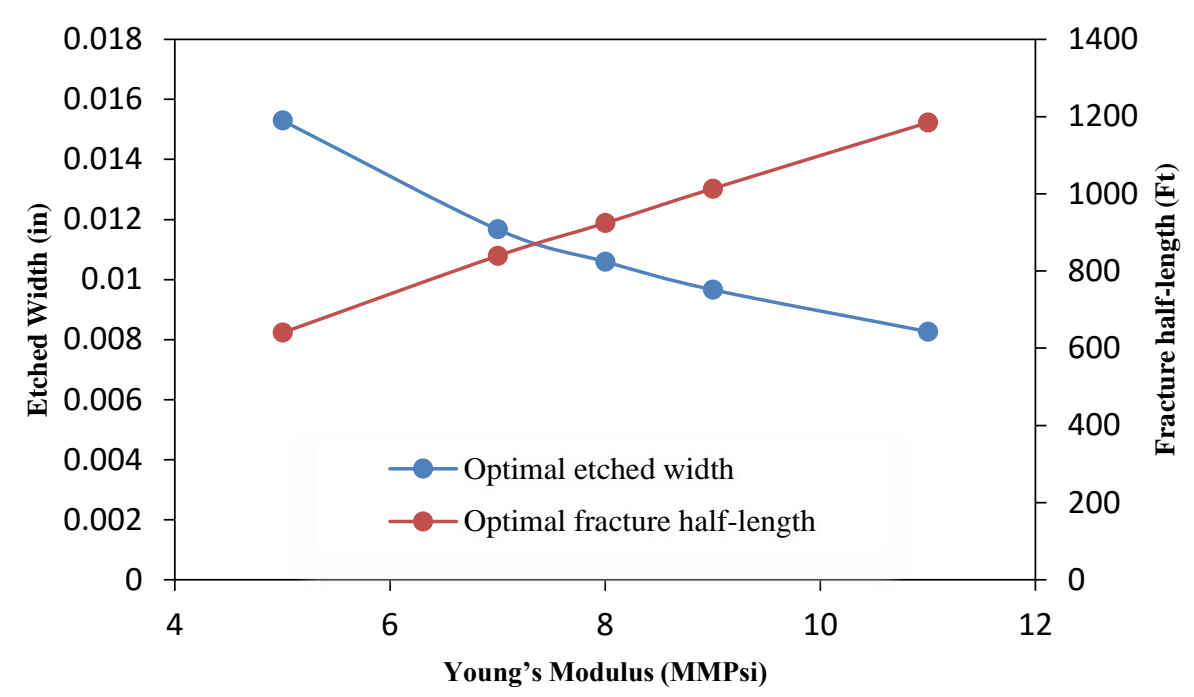

Figure 22. Optimal fracture half-length and etched width vs. Young's modulus.

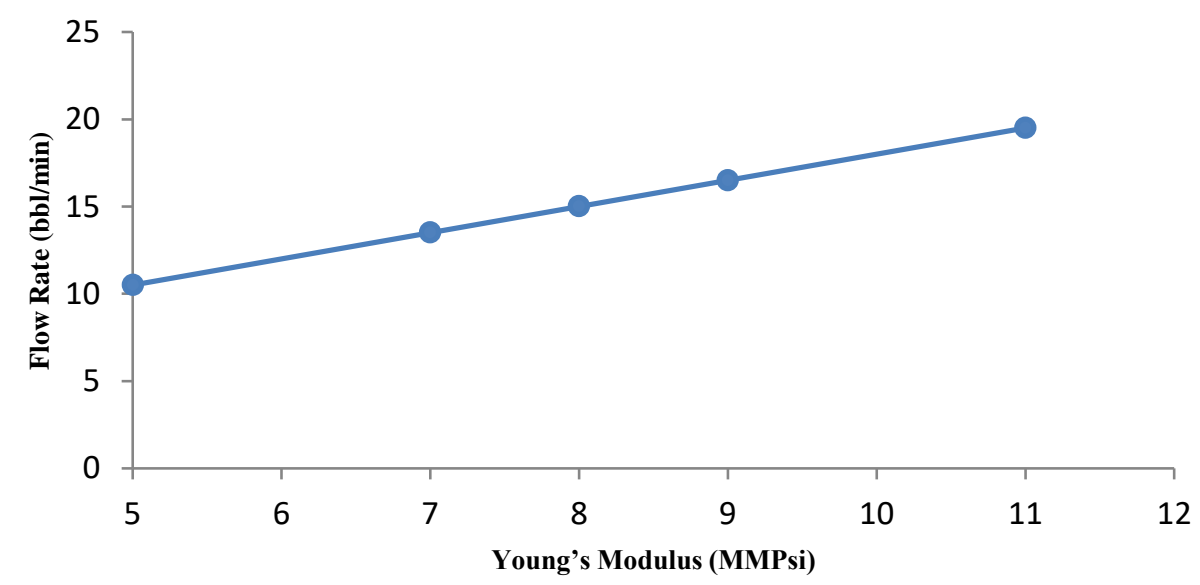

Figure 23. The effect of Young's modulus on the flow rate optimization for a $540 \mathrm{bbl}$ acid volume.

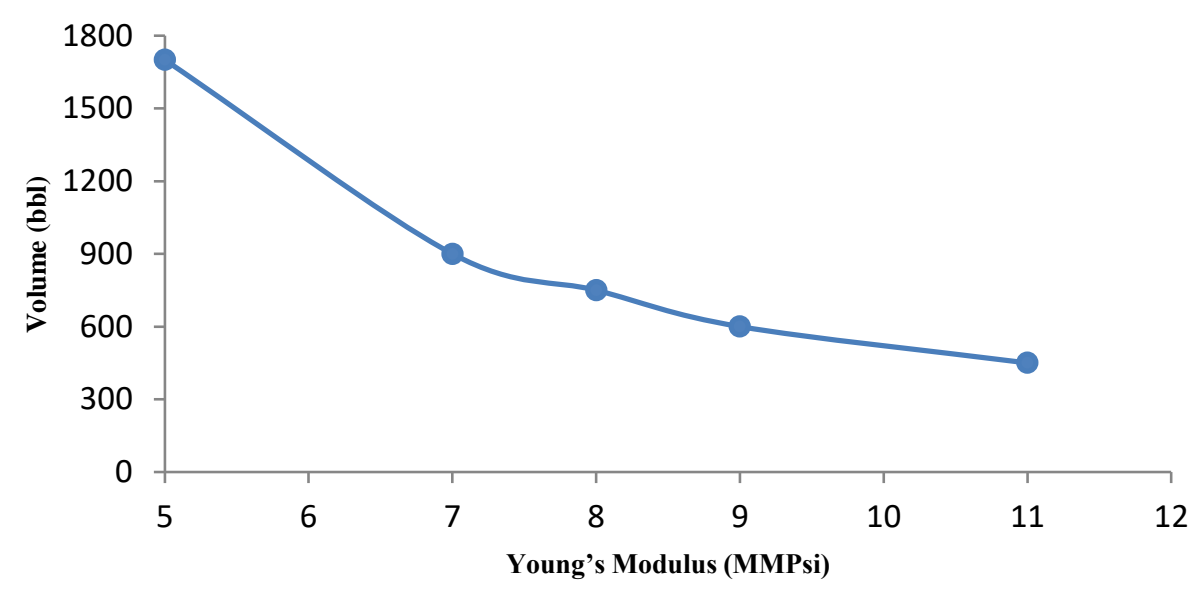

Figure 24. The effect of Young's modulus on the acid volume optimization. 


\subsection{Effect of the formation closure stress}

According to previous studies, the amount of formation closure stress directly affects fracture conductivity [28]. Besides, it indirectly affects the results of optimization of fracture geometry by the UFD method. Acid fracturing was suggested for formations with minimum horizontal stress (formation closure stress) less than 5000 Psi because the fracture face etching caused by the acid cannot support such high pressure[38]. Hence a 5000 Psi cut-off was considered for the formation closure stress. As the formation closure stress is increased, the calculated fracture half-length and average fracture width by the UFD method decrease and increase, respectively (Figure 25). Therefore, optimal fracture geometry conditions reach a low flow rate. The effect of closure stress on the optimal flow rate was investigated, and the results are presented in Figure 26. The effect of formation closure stress on acid volume is shown in Figure 27. As the optimal closure stress increases, the acid volume increases. If the closure stress is high, the volume of injected acid should be increased to achieve the optimal fracture geometry parameters with high probability.

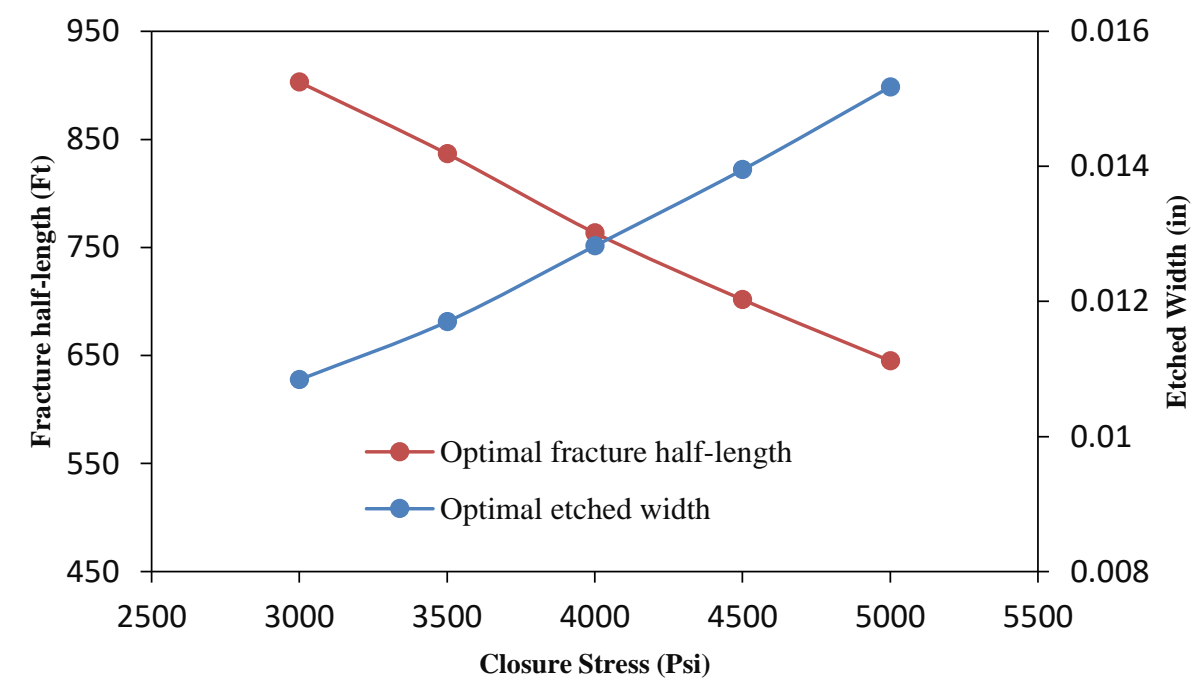

Figure 25. Optimal fracture half-length and etched width vs. Closure Stress.

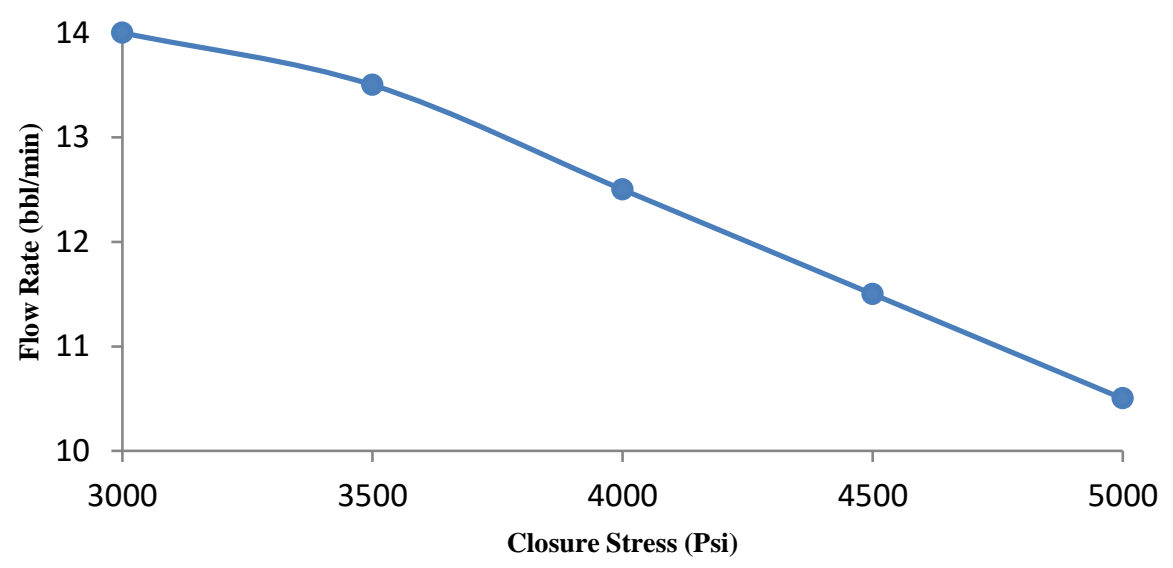

Figure 26. The effect of formation closure stress on the flow rate optimization for a $540 \mathrm{bbl}$ acid volume. 


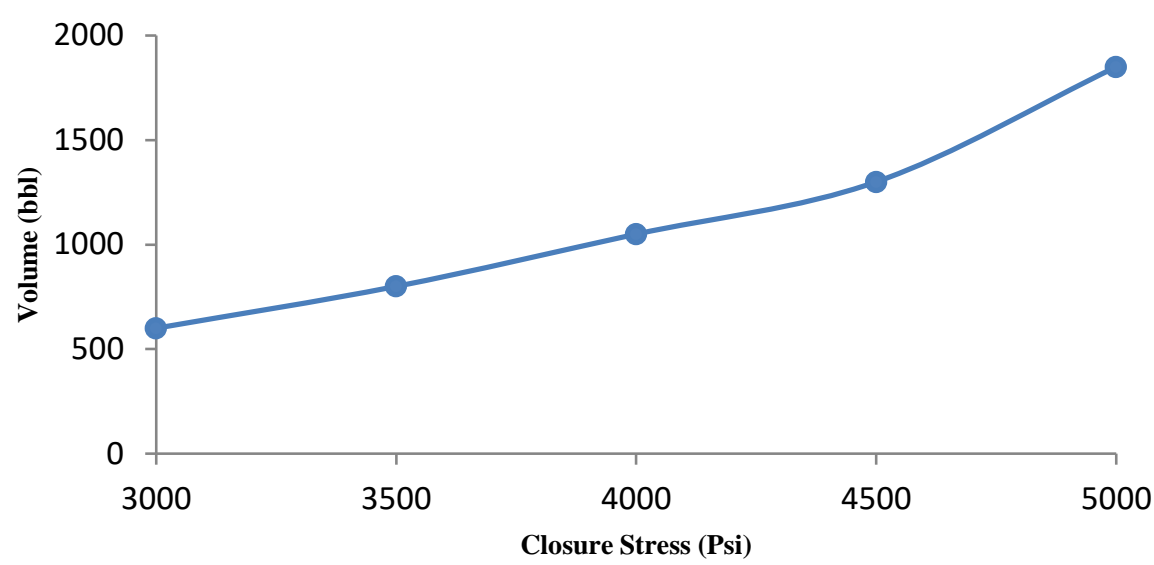

Figure 27. The effect of formation closure stress on the acid volume optimization.

\section{Conclusion}

This research presents a novel method for the optimum acid fracturing treatment and calculating the optimal fracture geometry parameters. So, a novel algorithm was performed to achieve the optimum fracture geometry parameters with the slightest uncertainty (maximum production index). UFD method was implemented to optimum fracture geometry parameters. The fracture propagation model was calculated by a Pseudo-3D analytical method. Besides, a numerical method was implemented to simulate the acid transport model. Based on this study, the following results can be summarized.

1. Due to the high volume of calculations, the simulation was performed with the proposed method for a specific case. The results have shown that the concentration of acid decreases along the fracture length and fracture walls. Acid-etched width and, consequently, conductivity decreases along the fracture length.

2. The flow rate optimization for $16 \%$ gelled acid showed that the optimization results are influenced by the acid transport behavior within the fracture.

3. The behavior of acid volume against minimum error (for a given volume) was investigated, and it was observed that the optimum flow rate increases with increasing the acid volume.

4. The parametric study showed that when formation permeability is decreased, the optimum fracture half-length and average fracture width increase and decrease, respectively. In this case, the optimum flow rate increases.

5. Fluid viscosity is a controllable parameter during acid fracturing operations. As the fluid viscosity increases, the optimum flow rate and volume of the injected acid decrease. Therefore, increasing the fluid's viscosity to a certain extent can improve the results of the acid fracturing treatment optimization. On the other hand, its excessive increase has no economic justification.

6. Sensitivity analysis on three types of acid systems showed that the optimum flow rate for straight acid is higher than the other two types of acid. It was also observed that for retarded acids, the optimum conditions reached only at a high acid volume.

7. The acid percentage is an influential parameter on the results. For a $15 \%$ acid concentration, the required flow rate is higher than $5 \%$ and $10 \%$. Also, the acid volume must be increased to achieve optimum conditions for a sample with a high acid concentration.

8. The parametric study showed that the optimum flow rate and acid volume increase and decrease for the high Young's modulus. In addition, the effect 
of closure stress was also investigated and observed for a sample with high closure stress, low flow rate, and high acid volume are required.

\section{Nomenclature}

\begin{tabular}{|c|c|}
\hline$C_{D}$ & Dimensionless acid concentration, dimensionless \\
\hline$C_{F D_{-} \mathrm{Opt}}$ & Optimum fracture conductivity, dimensionless \\
\hline$C_{L}$ & Leak-off coefficient, $\mathrm{Ft} / \sqrt{\operatorname{Min}}[\mathrm{m} / \sqrt{\mathrm{S}}]$ \\
\hline$C_{c}$ & Compressibility fluid-loss coefficient, $\mathrm{Ft} / \sqrt{\operatorname{Min}}[\mathrm{m} / \sqrt{\mathrm{S}}]$ \\
\hline$C_{\text {eqm }}$ & Acid equilibrium concentration, moles $/ \mathrm{m}^{3}$ \\
\hline$C_{i}$ & Injected-acid concentration, moles $/ \mathrm{m}^{3}$ \\
\hline$c_{t}$ & Total compressibility, 1/psi [m.s²/ kg] \\
\hline$C_{v}$ & Viscous fluid-loss coefficient, Ft $/ \sqrt{\operatorname{Min}}[\mathrm{m} / \sqrt{\mathrm{S}}]$ \\
\hline$C_{v, w h}$ & Viscous fluid-loss coefficient with wormhole, $\mathrm{Ft} / \sqrt{\operatorname{Min}}[\mathrm{m} / \sqrt{\mathrm{S}}]$ \\
\hline$C_{w}$ & Wall-building fluid-loss coefficient, $\mathrm{Ft} / \sqrt{\operatorname{Min}}[\mathrm{m} / \sqrt{\mathrm{S}}]$ \\
\hline $\bar{c}$ & Mean acid concentration \\
\hline$D_{\text {eff }}$ & Effective acid diffusion coefficient, $\mathrm{Ft}^{2} / \mathrm{min}\left[\mathrm{m}^{2} / \mathrm{s}\right]$ \\
\hline E & Young's modulus, psi $\left[\mathrm{kg} / \mathrm{m} . \mathrm{s}^{2}\right]$ \\
\hline$E_{f}$ & Reaction rate coefficient, $\frac{\mathrm{kg} \text { moles } \mathrm{HCl}}{\mathrm{m}^{2} \mathrm{~s}\left(\frac{\mathrm{kg} \text { moles } \mathrm{HCl}}{\mathrm{m}^{3} \text { acid solution }}\right)^{n^{\prime}}}$ \\
\hline
\end{tabular}

$f_{r} \quad$ Fraction of acid to react before leaking off, dimensionless

$G_{m} \quad$ Constant for the mean acid concentration profile

$h_{f} \quad$ Fracture height, $\mathrm{Ft}[\mathrm{m}]$

$k \quad$ Formation permeability, $\mathrm{md}\left[\mathrm{m}^{2}\right]$

$K \quad$ Consistency index, $\mathrm{lb} \cdot \mathrm{s}^{\mathrm{n}} / \mathrm{Ft}^{2}\left[\mathrm{~Pa} . \mathrm{s}^{\mathrm{n}}\right]$

$k_{f} \quad$ Fracture permeability, $\mathrm{md}\left[\mathrm{m}^{2}\right]$

$M W_{\text {acid }} \quad$ Molecular weight of the acid, gr/moles

$n$

Power in the power-law, dimensionless

$n^{\prime} \quad$ Reaction order, dimensionless

$N_{A} \quad$ Acid number, dimensionless

$N_{P e} \quad$ Peclet number

$N_{R e^{*}} \quad$ Reynolds number

$p \quad$ Fluid net pressure, $\mathrm{psi}\left[\mathrm{kg} / \mathrm{m} . \mathrm{s}^{2}\right]$

$\Delta p \quad$ Pressure difference between fracture and formation, $\mathrm{psi}\left[\mathrm{kg} / \mathrm{m} . \mathrm{s}^{2}\right]$

$q \quad$ Injected flow rate, $\mathrm{bbl} / \mathrm{min}\left[\mathrm{m}^{3} / \mathrm{s}\right]$

$Q_{i b t} \quad$ Number of PV's injected at wormhole breakthrough, dimensionless

$S_{p} \quad$ Spurt loss coefficient, Ft [m]

$t \quad$ Injection time, $\mathrm{s}$

$t_{0} \quad$ Time for acid to reach a particular point in the fracture, $\min [\mathrm{s}]$

$u \quad$ Velocity in the $x$ direction, $\mathrm{Ft} / \mathrm{min}[\mathrm{m} / \mathrm{s}]$

$v \quad$ Velocity in the $y$ direction, $\mathrm{Ft} / \mathrm{min}[\mathrm{m} / \mathrm{s}]$

$V_{\text {acid }} \quad$ Acid volume, bbl $\left[\mathrm{m}^{3}\right]$

$V_{f} \quad$ Induced fracture volume, $\mathrm{Ft}^{3}\left[\mathrm{~m}^{3}\right]$

$v_{i} \quad$ Velocity vector, $\mathrm{Ft} / \mathrm{min}[\mathrm{m} / \mathrm{s}]$

$v_{L} \quad$ Leak-off velocity, $\mathrm{Ft} / \mathrm{min}[\mathrm{m} / \mathrm{s}]$ 


$\begin{array}{ll}V_{r} & \text { Reservoir drainage volume, } \mathrm{Ft}^{3}\left[\mathrm{~m}^{3}\right] \\ w & \text { Velocity in the } z \text { direction, } \mathrm{Ft} / \mathrm{min}[\mathrm{m} / \mathrm{s}] \\ \bar{w} & \text { Averaged fracture width in pad stage, in [m] } \\ \bar{w}_{\text {Acid }} & \text { Estimated average acid-etched width, in [m] } \\ \bar{w}_{\iota} & \text { Average ideal fracture width, in [m] } \\ w_{\text {Opt }} & \text { Optimal fracture width, in [m] } \\ w k_{f} & \left.\text { Fracture conductivity, md-ft [m }{ }^{3}\right] \\ x_{f} & \text { Estimated fracture half-length, } \mathrm{Ft}[\mathrm{m}] \\ x_{\text {Old }} & \text { Initial guess for final } x_{\text {Opt }}, \mathrm{Ft}[\mathrm{m}] \\ x_{\text {Opt }} & \text { Optimal fracture half-length, } \mathrm{Ft}[\mathrm{m}]\end{array}$

Greek

Gravitational dissolving power, dimensionless

$\lambda_{D, x}$ Constant in equation 8 , dimensionless

$\lambda_{D, Z}$ Dimensionless horizontal correlation length, dimensionless

$\lambda_{m}$ Dimensionless vertical correlation length, dimensionless

$\sigma_{c}$ Eigenvalues for the mean acid concentration profile

$\sigma_{D}$ Closure stress, MMpsi $\left[\mathrm{kg} / \mathrm{m} . \mathrm{s}^{2}\right]$

$\sigma_{D}$ Dimensionless standard deviation of permeability, dimensionless Formation porosity, dimensionless $\rho$ Fluid density, $\mathrm{lbm} / \mathrm{Ft}^{3}\left[\mathrm{~kg} / \mathrm{m}^{3}\right]$

Poisson ratio, dimensionless

$\mu$ Fracture-fluid viscosity of Newtonian fluid, cp [kg/m.s] Acid viscosity, cp [kg/m.s]

Volumetric dissolving power, dimensionless

\section{References}

1. L.D. Roberts, J.A. Guin, Effect Of Surface Kinetics In Fracture Acidizing., Soc Pet Eng Aime J. 14 (1974) $385-395$. Https://Doi.Org/10.2118/4349-Pa.

2. B.B. Williams, D.E. Nierode, Design Of Acid Fracturing Treatments., Jpt, J. Pet. Technol. 24 (1972) 849-859. Https://Doi.Org/10.2118/3720-Pa.

3. A.W. Coulter, E.N. Alderman, J.E. Cloud, C.W. Crowe, Mathematical Model Simulates Actual Well Conditions In Fracture Acidizing Treatment Design, In: Society Of Petroleum Engineers (Spe), (1974). Https://Doi.Org/10.2118/5004-Ms.

4. R.S. Schechter, Oil Well Stimulationitle, Englewood Cliffs, New Jersey Prentice-Hall, Inc. (1992).

5. A.S. Berman, Laminar Flow In Channels With Porous Walls, J. Appl. Phys. 24 (1953) $1232-1235$. Https://Doi.Org/10.1063/1.1721476.

6. A.D. Hill, D. Zhu, Y. Wang, Effect Of Wormholing On The Fluid-Loss Coefficient In Acid Fracturing, Spe Prod. Facil. 10 (1995) 257-263. Https://Doi.Org/10.2118/27403-Pa.

7. A.D. Gdanski, W.S. Lee, On The Design Of Fracture Acidizing Treatments, In: Society Of Petroleum Engineers - Spe Production Operations Symposium, Pos 1989. Society Of Petroleum Engineers, Pp. 539-546, Pp. 539-546 (1989). Https://Doi.Org/10.2118/18885-Ms.

8. R. Navarrete, M. Miller, J. Gordon, Laboratory And Theoretical Studies For Acid Fracture Stimulation Optimization, Paper Spe 39776 Presented At The 1998 Spe Permian Basin Oil And Gas Recovery Conference, Midland, Texas, 23-26 March (1998). Https://Onepetro.Org/Conference-Paper/Spe-39776-Ms.

9. K.K. Lo, R Dean, Modeling Of Acid Fracturing, Spe Prod. Eng, 4(2): 194-200;Trans., Aime, 287 (1989). Spe-17110-Pa. Doi: 10.2118/17110-Pa. 
10. A. Settari, R. Sullivan, C. Hansen, A New Two-Dimensional Model For Acid-Fracturing Design. (2001). Https://Onepetro.Org/Po/Article-Abstract/16/04/200/74756.

11. J. Romero, H. Gu, S.N. Gulrajani, 3d Transport In Acid-Fracturing Treatments: Theoretical Development And Consequences For Hydrocarbon Production, (2001). Https://Onepetro.Org/Journal-Paper/Spe-72052-Pa.

12. J. Mou, D. Zhu, A.D. Hill,. Journal, Acid-Etched Channels In Heterogeneous Carbonates - A Newly Discovered Mechanism For Creating Acid-Fracture Conductivity, (2010). Https://Onepetro.Org/Sj/Article-Abstract/15/02/404/192264.

13. C. Oeth, A.D. Hill, D. Zhu. Technology, Acid Fracture Treatment Design With Three-Dimensional Simulation, (2014). Https://Onepetro.Org/Conference-Paper/Spe-168602-Ms.

14. M.S. Aljawad, D. Zhu, A.D. Hill, Modeling Study Of Acid Fracture Fluid System Performance, In: Soc. Pet. Eng - Spe Hydraul. Fract. Technol. Conf. Hftc 2016, Society Of Petroleum Engineers, (2016). Https://Doi.Org/10.2118/179109-Ms.

15. M.M. Alhubail, A. Misra, R. Barati, A Novel Acid Transport Model With Robust Finite Element Discretization, In: Soc. Pet. Eng. - Spe Kingdom Saudi Arab. Annu. Tech. Symp. Exhib. 2017, Society Of Petroleum Engineers, (2017): Pp. 1453-1469. Https://Doi.Org/10.2118/188030-Ms.

16. A. Ugursal, M.P. Schwalbert, D. Zhu, A. Daniel Hill, Acid Fracturing Productivity Model For Naturally Fractured Carbonate Reservoirs, In: Soc. Pet. Eng - Spe Int. Hydraul. Fract. Technol. Conf. Exhib. 2018, Ihft 2018, Society Of Petroleum Engineers, (2018). Https://Doi.Org/10.2118/191433-18ihft-Ms.

17. L. Dang, C. Zhou, M. Huang, D. Jiang, Simulation Of Effective Fracture Length Of Prepad Acid Fracturing Considering Multiple Leak-Off Effect, Nat. Gas Ind. B. 6 (2019) 64-70. Https://Doi.Org/10.1016/J.Ngib.2019.01.009.

18. K. Ben-Naceur, M.J. Economides, Design And Evaluation Of Acid Fracturing Treatments, Paper Spe 18978 Presented At The Spe Joint Rocky Mountain Regional/Low Permeability Reservoirs Symposium And Exhibition, Denver, Colorado, 6-8 March. (1989). Https://Onepetro.Org/Conference-Paper/Spe-18978-Ms.

19. J. Guo, Y. Li, J. Zhao, J. Luo, Research Of Three-Dimensional Model For Acid Fracturing And Optimum Design For The Treatments, In: Can. Int. Pet. Conf. 2004, Cipc 2004, Petroleum Society Of Canada (Petsoc), (2004). Https://Doi.Org/10.2118/2004-011.

20. A. Ravikumar, M. Marongiu-Porcu, A. Morales, Optimization Of Acid Fracturing With Unified Fracture Design, In: Soc. Pet. Eng. - Abu Dhabi Int. Pet. Exhib. Conf. Adipec 2015, Society Of Petroleum Engineers, (2015). Https://Doi.Org/10.2118/177486Ms.

21. K. Ai, L. Duan, H. Gao, G. Jia, Hydraulic Fracturing Treatment Optimization For Low Permeability Reservoirs Based On Unified Fracture Design, Energies. 11 (2018) 1720. Https://Doi.Org/10.3390/En11071720.

22. M.S. Aljawad, M.P. Schwalbert, D. Zhu, A.D. Hill, Optimizing Acid Fracture Design In Calcite Formations: Guidelines Using A Fully Integrated Model, In: Spe Prod. Oper., Society Of Petroleum Engineers, (2020): Pp. 161-177. Https://Doi.Org/10.2118/198912-Pa.

23. M.S. Aljawad, D. Zhu, A.D. Hill, Temperature And Geometry Effects On The Fracture Surfaces Dissolution Patterns In Acid Fracturing, In: Soc. Pet. Eng - Spe Eur. Featur. 80th Eage Conf. Exhib. 2018, Society Of Petroleum Engineers, (2018). Https://Doi.Org/10.2118/190819-Ms.

24. M.S. Aljawad, Impact Of Diversion On Acid Fracturing Of Laminated Carbonate Formations: A Modeling Perspective, Acs Omega. 5 (2020) 6153-6162. Https://Doi.Org/10.1021/Acsomega.0c00178.

25. A. Al-Ameri, T. Gamadi, Optimization Of Acid Fracturing For A Tight Carbonate Reservoir, Petroleum. 6 (2020) $70-79$. Https://Doi.Org/10.1016/J.Petlm.2019.01.003.

26. A. Hassan, M.S. Aljawad, M. Mahmoud, An Artificial Intelligence-Based Model for Performance Prediction of Acid Fracturing in Naturally Fractured Reservoirs, Acs Omega. 6 (2021) 13654-13670. Https://doi.org/10.1021/acsomega.1c00809.

27. M.J. Valko, P., Economides, Hydraulic Fracturing Mechanics, John Wiley And Sons, England.(1995).

28. J. Deng, J. Mou, A.D. Hill, D. Zhu, A New Correlation Of Acid-Fracture Conductivity Subject To Closure Stress, In: Spe Prod. Oper., Society Of Petroleum Engineers, (2012): Pp. 158-169. Https://Doi.Org/10.2118/140402-Pa.

29. Economides, M.J., Oligney, R.E., Valko, P.P, Unified Fracture Design. Orsa Press,Alvin, Texas. (2002).

30. Crank, J. Free And Moving Boundary Problems. New York: Clarendon Press, (1984).

31. J. Mou, Modeling Acid Transport And Non-Uniform Etching In A Stochastic Domain In Acid Fracturing. Ph.D. dissertation, College Station: Texas A\&M University, (2009).

32. S. Acharya, F.H. Moukalled, Improvements To Incompressible Flow Calculation On A Nonstaggered Curvilinear Grid, Numer. Heat Transf. Part B Fundam. 15 (1989) 131-152. Https://Doi.Org/10.1080/10407798908944897.

33. Penny, G.S., Conway, M.W., Fluid Leakoff. In Recent Advances In Hydraulic Fracturing, Eds. Gidley, J.L., Holditch, S.A., Nierode, D.E., And Veatch, Jr., R.W. , 147-176. Richardson, Texas: Society Of Petroleum (1989).

34. A. Settari, Modeling Of Acid-Fracturing Treatments, Spe Prod. Facil. 8 (1993) 30-38. Https://Doi.Org/10.2118/21870-Pa.

35. K. Ben-Naceur, M.J. Economides, Design And Evaluation Of Acid Fracturing Treatments, In: Low Permeability Reserv. Symp., Society Of Petroleum Engineers, (1989). Https://Doi.Org/10.2118/18978-Ms.

36. R.M. Terrill, Heat Transfer In Laminar Flow Between Parallel Porous Plates, Int. J. Heat Mass Transf. 8 (1965) $1491-1497$. Https://Doi.Org/10.1016/0017-9310(65)90034-7.

37. J. De Rozieres, F.F. Chang, R.B. Sullivan, Measuring Diffusion Coefficients In Acid Fracturing Fluids And Their Application To Gelled And Emulsified Acids, In: Spe Annu. Tech. Conf. Exhib., Society Of Petroleum Engineers, (1994). Https://Doi.Org/10.2118/28552-Ms.

38. P. Valko, L. Norman, A. Daneshy, Petroleum Well Construction (Book) I Etdeweb. Chapter 17, Well Stimulation, Wiley, P. 506. (1998). Https://Www.Osti.Gov/Etdeweb/Biblio/300026. 